\title{
Global Climatological Features in a Simulation Using the CPTEC-COLA AGCM
}

\author{
Iracema F. A. Cavalcanti, José A. Marengo, Prakki Satyamurty, Carlos A. Nobre, \\ Igor Trosnikov, José Paulo Bonatti, Antonio Ocimar Manzi, Tatiana Tarasova, Luciano P. Pezzi, \\ Cassiano D’Almeida, Gilvan Sampaio, Christopher C. Castro, Marcos B. Sanches, and \\ HÉlio CAMARGo \\ Center for Weather Forecasting and Climate Studies/National Institute for Space Research, Cachoeira Paulista, São Paulo, Brazil
}

(Manuscript received 9 October 2001, in final form 5 April 2002)

\begin{abstract}
The Center for Weather Forecasting and Climate Studies-Center for Ocean-Land-Atmosphere Studies (CPTECCOLA) atmospheric general circulation model (AGCM) is integrated with nine initial conditions for $10 \mathrm{yr}$ to obtain the model climate in an ensemble mode. The global climatological characteristics simulated by the model are compared with observational data, and emphasis is given to the Southern Hemisphere and South America. Evaluation of the model's performance is presented by showing systematic errors of several variables, and anomaly correlation and reproducibility are applied to precipitation. The model is able to simulate the main features of the global climate, and the results are consistent with analyses of other AGCMs. The seasonal cycle is reproduced well in all analyzed variables, and systematic errors occur at the same regions in different seasons. The Southern Hemisphere convergence zones are simulated reasonably well, although the model overestimates precipitation in the southern portions and underestimates it in the northern portions of these systems. The high- and low-level main circulation features such as the subtropical highs, subtropical jet streams, and storm tracks are depicted well by the model, albeit with different intensities from the reanalysis. The stationary waves of the Northern and Southern Hemispheres are weaker in the model; however, the dominant wavenumbers are similar to the observations. The energy budget analysis shows values of some radiative fluxes that are close to observations, but the unbalanced fluxes in the atmosphere and at the surface indicate that the radiation and cloud scheme parameterizations need to be improved. Besides these improvements, changes in the convection scheme and higher horizontal resolution to represent orographic effects better are being planned to improve the model's performance.
\end{abstract}

\section{Introduction}

General circulation models have been used in climate simulations to study climate variability, climate change, and seasonal prediction and also to examine their ability to describe the main features of the atmosphere. Results of long-term integrations, as in Gates et al. (1999), are important to provide the model climatology and to perform model validation. It is desirable that the model simulates well the observed climate and its variability, giving confidence for its applicability. Climate simulations have shown the ability of different models in representing observed characteristic features of the atmospheric circulation and precipitation (Hurrell et al. 1998; Gates et al. 1999; Johns et al. 1997; Pope et al. 2000). However, the intensity and geographical distribution of these variables may differ greatly in each model. The continuous increase of computer power enables increased model resolution, sophisticated parameterization schemes, and large numbers of integrations, which can lead to an improved simulation of atmo-

Corresponding author address: Iracema F. A. Cavalcanti, CPTEC/ INPE, Rod Presidente Dutra, Km. 40, Cachoeira Paulista, São Paulo, CEP 12260000, Brazil.

E-mail: iracema@cptec.inpe.br spheric behavior (Brankovic and Molteni 1997; Déqué et al. 1994). The chaotic behavior of the atmosphere made the ensemble technique a necessary tool to reduce the effect of the initial conditions (Murphy 1988).

A detailed performance analysis of the National Center for Atmospheric Research (NCAR) Community Climate Model, version 3, (CCM3) was documented in Hurrell et al. (1998), Kiehl et al. (1998), and Hack et al. (1998) in which different aspects of the simulated climatology were discussed. Features of the simulated climatological precipitation and atmospheric fields using the Canadian Climate Centre GCM were also discussed by McFarlane et al. (1992).

Several GCMs were used in the Atmospheric Model Intercomparison Project (AMIP) to simulate the presentday climate and to analyze the results related to different parameterizations and resolutions but subjected to the same SST boundary condition (Gates 1992; Gates et al. 1999). Global hydrological processes were discussed in Lau et al. (1996), comparing results from 29 models. The global mean surface air temperature and precipitation over land were shown in a scatterplot diagram, which indicated how well the model results compared with the observations. Although there was large variability among models, the ensemble mean results of all models were 
very close to the observations. An important result of that study was to show the deficiency of all models in simulating the light rain rates $\left(<1 \mathrm{~mm} \mathrm{day}^{-1}\right)$. This result was a reflection of the poorly represented low-level stratocumulus and shallow convection. The ensemble of the models overestimated the rainfall in the Tropics and underestimated it in the extratropics. Other results of AMIP were discussed in Gates et al. (1999), who showed the model's ensemble errors of several variables. The largest errors of the ensemble mean were found in the cloudiness and $200-\mathrm{hPa}$ temperature, and the smallest errors were identified in the surface air temperature. The need for further work to reduce the errors of the atmospheric GCMs was outlined by Gates et al. (1999) following the analyses of AMIP results. The problems still under consideration were parameterization of clouds and their radiative interactions, parameterization of convection and precipitation, and the hydrologic processes.

Seasonal climate simulation results from the original version of the Center for Ocean-Land-Atmosphere Studies (COLA) AGCM (R40 L18) were discussed in Shukla et al. (2000b). They showed the mean model errors for January-March and anomalies during ENSO episodes. Other results from the COLA AGCM were shown in the AMIP hydrological processes analyses and, when compared with other models, it was classified in the second quartile of model ranking (Lau et al. 1996). This model is the precursor of CPTEC-COLA AGCM, a model that has been used at the Center for Weather Prediction and Climate Studies (CPTEC) in São Paulo, Brazil, for midrange weather forecasts and seasonal predictions since 1995. Seasonal predictions for the rainy season of northeast Brazil, using this model, have been published in the experimental long-lead forecast bulletin (Cavalcanti et al. 1999, 2000).

In this study, results from a climate simulation obtained by running the CPTEC-COLA AGCM for 10 model years in an ensemble mode are discussed. The main goal is to provide a global view of the climatological features simulated by the model and to show the ability of the model to reproduce seasonal cycle and energy budget. In the discussions emphasis is on the Southern Hemisphere climatological characteristics and seasonal variability. A brief discussion is made related to the simulation of ENSO aspects during the period of model integration. A description of the model and the changes introduced by CPTEC in the original COLA version, as well as available datasets for validation, is presented in section 2 . The climatological features are shown in section 3. Aspects related to El Niño-Southern Oscillation are discussed in section 4, and maps of anomaly correlations and reproducibility are shown in section 5. Discussions and conclusions are summarized in section 6.

\section{Model description, experiment design, and data used for validation}

a. Model description

The CPTEC-COLA GCM is a modified version of the spectral COLA GCM, which was adapted from the Na- tional Centers for Environmental Prediction (NCEP) GCM. A land surface module [Simplified Simple Biosphere Model (SSiB)] that considers the vegetation influence in a sophisticated manner (Xue et al. 1991) was introduced by COLA. Other modifications by COLA were related to radiation and cloud-radiation interactions and treatment of vertical diffusion. These modifications are documented in Sato et al. (1989) and Hou (1990). The COLA AGCM now has two options for convective precipitation, the Kuo scheme (Kuo 1974) and the relaxed Arakawa-Schubert (RAS) scheme (Moorthi and Suarez 1992).

The dynamical and physical processes in the COLA model are described in Kinter et al. (1997). The CPTEC-COLA model dynamical processes and physical parameterizations are the same as those of the COLA model, with Kuo scheme for deep convection (Kuo 1974), shallow convection following Tiedtke (1983), Mellor and Yamada closure scheme applied for the vertical diffusion in the planetary boundary layer (Mellor and Yamada 1982), and biharmonic-type diffusion for the horizontal diffusion, which is necessary to control small-scale noise. The shortwave radiation is that of Lacis and Hansen (1974), modified by Davies (1982), and the longwave radiation formulation was that developed by Hashvardhan et al. (1987). Cloud-radiation interaction considers predicted clouds using a hybrid scheme of Hou (1990) and the NCAR CCM2 scheme (Kiehl et al. 1994). The Hou scheme is based on the cloud prediction method of Slingo (1987).

The prescribed surface variable is monthly observed sea surface temperature (SST). The surface variables determined by the climate model are land surface temperature, soil moisture, surface albedo, and snow depth, which are introduced in the beginning of the integration with climatological values and are adjusted during the integration. Sea ice is considered at grid points for which SST is below $-2^{\circ} \mathrm{C}$. Surface temperature and soil moisture climatological data are taken from Willmott et al. (1985). Albedo is specified as a function of solar zenith angle over the ocean and is predicted by $\mathrm{SSiB}$ over the land. The snow depth is also applied as an initial condition based on the time-interpolated surface climatological albedo on the initial date of the model run (Kinter et al. 1997). Climatological albedo is based on Posey and Clapp (1954). Ozone concentration is taken from a climatological table that gives values at each $5^{\circ}$ of latitude for each sigma level and has different values for each season, compiled by the National Meteorological Center (NMC) Development Division Staff (1988). Carbon dioxide concentration was considered to be a constant value of $345 \mathrm{ppm}$. The upper boundary condition is that the vertical velocity at the top of the atmosphere must be zero to satisfy mass conservation (Kinter et al. 1997).

The main changes introduced by CPTEC in the COLA GCM are related to truncation type, dissipation process, computer performance, postprocessing scheme, and increased number of vertical levels. The truncation, 
which was rhomboidal in the COLA AGCM, is changed to triangular. In triangular truncation, the horizontal resolution in the zonal and meridional directions is nearly the same. Another desirable property is that the choice of the North Pole has no impact on the spectral filter for a high-resolution model. In rhomboidal truncation, the latitudinal resolution is the same for every zonal wavenumber. At high resolution, the triangular truncation appears to be superior (Holton 1992). All model numerical codes are rewritten considering triangular truncation. New compilation options are introduced to adapt the model to an NEC, Inc., NEC-SX3/SX4 supercomputer. There are modifications to improve the vectorization process, to reduce the computational time, and to include the parallelization process. To prevent computational instability that arises from strong winds, an additional dissipation (Newtonian dissipation) is introduced in the wind tendency in the stratosphere. For diagnostic purposes, the temperature and humidity inside the mountains are calculated using a constant surface relative humidity instead of a constant adiabatic rate. Streamfunction and velocity potential fields are adjusted to wind field in pressure coordinates.

The model resolution in this simulation is T62 L28, which represents triangular truncation of 62 waves in the horizontal coordinate and 28 levels in the vertical sigma coordinate (21 in the troposphere and 7 in the stratosphere).

\section{b. Simulation design}

The climate simulation is performed in an ensemble mode, integrating the model with nine different initial conditions derived from nine consecutive days of European Centre for Medium-Range Weather Forecasts (ECMWF) daily analyses, from 11 to 19 November 1981. Spectral data of temperature, zonal and meridional wind components, and relative humidity are transformed to spectral coefficients of virtual temperature, divergence, vorticity, specific humidity, and logarithm of pressure, which are the initial conditions for each day. Surface pressure is calculated from the geopotential height, temperature, and topography. Monthly observed SST from the NCEP Climate Prediction Center optimum interpolated SST dataset (Reynolds and Smith 1994) are applied as boundary conditions, from November 1981 to December 1991.

The results are analyzed for January 1982-December 1991 , considering the seasonal averages for each variable. Ensemble means are used to compare the model results with observational datasets. Global energy fluxes, albedo, and cloud fraction are calculated to obtain the model energy budget. The variables analyzed in spatial fields are precipitation, sea level pressure, the wind field at 850 and $200 \mathrm{hPa}$, and geopotential height at 200 $\mathrm{hPa}$. Precipitation fields are shown for all seasons; the other variables are shown for December-January-February (DJF) and June-July-August (JJA). Zonal mean vertical cross sections are shown for zonal wind component and air temperature, and zonal averages of precipitation, sea level pressure, and wind field at $200 \mathrm{hPa}$ are discussed to indicate the global latitudinal variation.

\section{c. Data used for model evaluation}

Global and regional precipitation fields are derived from the Climate Prediction Center merged analysis precipitation (CMAP) data (Xie and Arkin 1997) available for 1979-96. The CMAP dataset uses several estimates of precipitation as measured by satellite over land and oceans, as well as the rain gauge data over land. In this study, only data in the period of the model integration (1982-91) were used to compare with the model seasonal climatology. The corrected gauge-derived rainfall climatology of Legates and Willmott (1990) is also used to compare the latitudinal variability of zonal average precipitation. This dataset includes shipboard rain gauge corrected data interpolated on a grid of $0.5^{\circ}$ latitude $\times$ $0.5^{\circ}$ longitude. In this dataset, the climatology is considered for the period of 1920-80, with greater weight given to the more recent years.

The NCEP-NCAR reanalysis (Kalnay et al. 1996) is used to validate wind fields, sea level pressure, temperature, and geopotential height. In places for which there are few observations, these datasets can deviate from the real atmosphere and need to be considered cautiously. Artificial pressure trends in the reanalysis data at high latitudes of the Southern Hemisphere were reported by Hines et al. (2000). These trends were smaller during the period of the current analyses, but the pressure magnitudes were higher than the observations. Therefore, comparisons of the model simulation results with reanalysis data close to Antarctica can show artificial bias. Fluxes for the energy budget analysis are taken from estimates of Kiehl and Trenberth (1997). These can also contain some errors, since they are inferred from models.

\section{Climatological features}

\section{a. Energy budget}

The global energy budget is presented in Tables 1 and 2 , which contain model results and observational estimates from Kiehl and Trenberth (1997). The budget is analyzed at the top of the atmosphere and at the surface. Table 1 shows that the net shortwave radiative flux (SW) at the top of the atmosphere is higher in the model than in the observations by $14 \mathrm{~W} \mathrm{~m}^{-2}$ in all-sky conditions and by $9 \mathrm{~W} \mathrm{~m}^{-2}$ in clear-sky conditions. The difference is related partially to the underestimation of the cloud fraction in the model (9\% less cloud cover) and to the subsequent underestimation of the SW cloud radiative forcing. The neglect of the aerosol effect in the model and the underestimation of the surface albedo (4\% lower than the climatological value) also contribute to the difference.

A reasonable agreement is obtained between the sim- 
TABLE 1. Ensemble annual global energy budget at the top of the atmosphere (TOA). The SW and LW radiative fluxes and cloud radiative forcing are in $\mathrm{W} \mathrm{m}^{-2}$. Cloud fraction and albedo are displayed in percent. Sign convention is positive for downward flux.

\begin{tabular}{lcc}
\hline \hline & Observed & CPTEC-COLA \\
\hline SW downward & +342 & +341 \\
SW NET & +235 & +249 \\
SW clear-sky net & +286 & +295 \\
Albedo & 31 & 27 \\
OLR & -235 & -239 \\
OLR clear sky & -265 & -268 \\
SW upward & -107 & -92 \\
Cloud fraction & 62 & 53 \\
SW cloud forcing & -51 & -46 \\
LW cloud forcing & +29 & +29 \\
Net TOA & 0 & +10 \\
\hline
\end{tabular}

ulated and the observed values of the outgoing longwave radiation (OLR). The difference is about 3-4 W $\mathrm{m}^{-2}$ in all-sky conditions and in clear-sky conditions. Note that the longwave cloud radiative forcing is better simulated than the shortwave cloud radiative forcing. The model shows slightly larger values of OLR but, as mentioned, not enough to balance the incoming SW radiation at the top of the atmosphere. The surface radiation budget is presented in Table 2. The model also overestimates the net shortwave radiative flux at the surface in all-sky conditions and in clear-sky conditions by $22-23 \mathrm{~W} \mathrm{~m}^{-2}$. This overestimate is related to the overestimation of the downward shortwave flux in the clear-sky conditions (about $9 \mathrm{~W} \mathrm{~m}^{-2}$ ), to the underestimation of the surface albedo value (contributing to a larger SW absorption of about $8.5 \mathrm{~W} \mathrm{~m}^{-2}$ ), and to the magnitude of the cloud fraction. The net longwave radiation in the model is underestimated by $3 \mathrm{~W} \mathrm{~m}^{-2}$, latent heat flux is overestimated by $24 \mathrm{~W} \mathrm{~m}^{-2}$, and sensible heat flux is underestimated by $4 \mathrm{~W} \mathrm{~m}^{-2}$. Overall, there is an excess of SW energy of $6 \mathrm{~W} \mathrm{~m}^{-2}$ that is not balanced by longwave (LW) radiation, latent heat $(\mathrm{LH})$, and sensible heat $(\mathrm{SH})(\mathrm{SW}=\mathrm{LW}+\mathrm{LH}+\mathrm{SH})$. The global precipitation is overestimated by $0.8 \mathrm{~mm}$ day $^{-1}$. Global evaporation, calculated using the simulated latent flux, is $3.5 \mathrm{~mm} \mathrm{day}{ }^{-1}$, equal to the precipitation rate, giving a well-balanced hydrological budget.

In addition to this analysis, the fluxes are calculated for the land areas and for the oceans and are shown in Table 3. Over the continent the imbalance (residual heat) is about $3 \mathrm{~W} \mathrm{~m}^{-2}$; over the ocean it is about $8 \mathrm{~W} \mathrm{~m}^{-2}$. The larger latent heat flux implies larger evaporation, and the excess of humidity leads to larger global precipitation, since the model precipitable water is even less than the observed value. The imbalance may be also due to the existing deficiencies in the numerical schemes to calculate heat fluxes. The Bowen ratio calculated over land is 1.0 in the model, as compared with the observed value of 0.96, although both latent and sensible heat fluxes are higher in the model. However, over the ocean the Bowen ratio is 0.09 , and the observed climatological value is 0.11 . This difference is due to
TABLE 2. Ensemble annual global surface energy budget. The SW and LW radiative fluxes and latent and sensible heat fluxes are displayed in $\mathrm{W} \mathrm{m}^{-2}$, precipitation is in $\mathrm{mm} \mathrm{day}^{-1}$, and precipitable water is in $\mathrm{mm}$.

\begin{tabular}{lcc}
\hline \hline & Observed & CPTEC-COLA \\
\hline SW net & +168 & +191 \\
Clear-sky SW net & +217 & +239 \\
LW upward & -390 & -398 \\
LW downward & +324 & +335 \\
LW net & -66 & -63 \\
Clear-sky LW upward & -390 & -398 \\
Clear-sky LW downward & +278 & +307 \\
Clear-sky LW net & -112 & -91 \\
Latent heat flux & -78 & -102 \\
Sensible heat flux & -24 & -20 \\
Net surface & 0 & +6 \\
Precipitation & 2.7 & 3.5 \\
Precipitable water & 25.5 & 23.9 \\
\hline
\end{tabular}

the higher latent heat over the ocean in the model (124 $\mathrm{W} \mathrm{m}{ }^{-2}$ ) against $98 \mathrm{~W} \mathrm{~m}^{-2}$ calculated in climatological analysis of Baumgartner and Reichel (1975). The sensible heat flux over the ocean is $11 \mathrm{~W} \mathrm{~m}^{-2}$ in the model and in the observed climatology.

The analysis indicates that the SW radiative transfer code and the cloud cover scheme employed in the model need to be improved. The parameterization of evaporation over the ocean also needs a revision.

\section{b. Zonal means of precipitation, sea level pressure, and high-level zonal wind}

A useful overview of the accuracy of the ensemble model climatology is given by zonally averaged statistics. The results for DJF and JJA extremes of the annual cycle are shown in Figs. 1a,b. The zonally averaged precipitation is better simulated in JJA in the Northern Hemisphere $(\mathrm{NH})$, comparing very well with the Legates and Willmott (1990) and CMAP climatologies. The model, in general, significantly overestimates the precipitation in comparison with the observed datasets in the Southern Hemisphere (SH), but the minima associated with the subtropical highs and maxima related to the midlatitude storm tracks in both hemispheres are reproduced by the model.

In DJF, there are more discrepancies between the model and the observational rainfall datasets, but the model can capture important features such as the double maximum in the tropical region and the storm-track region of both hemispheres. The minima associated with the subtropical highs are simulated and have closer values to CMAP in the SH. During both seasons, modeled precipitation rates are higher than the observed estimates from CMAP over the midlatitude storm tracks, except when compared with the Legates and Willmott rainfall rates in DJF in SH.

Other models, such as CCM3 (Hurrell et al. 1998), the second Hadley Centre Coupled Ocean-Atmosphere General Circulation Model (HadCM3; Johns et al. 1997), and 
TABLE 3. Ensemble annual surface energy budget over land and over the ocean.

\begin{tabular}{|c|c|c|c|c|c|}
\hline & 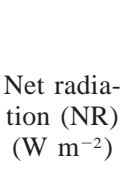 & $\begin{array}{l}\text { Latent heat } \\
\qquad(\mathrm{LH}) \\
\left(\mathrm{W} \mathrm{m} \mathrm{m}^{-2}\right)\end{array}$ & $\begin{array}{c}\text { Sensible } \\
\text { heat }(\mathrm{SH}) \\
\left(\mathrm{W} \mathrm{m}^{-2}\right)\end{array}$ & $\begin{array}{c}\text { Residual } \\
\text { heat }(\mathrm{RH}) \\
(\mathrm{NR}-\mathrm{LH} \\
-\mathrm{SH}) \\
\left(\mathrm{W} \mathrm{m} \mathrm{m}^{-2}\right)\end{array}$ & RH/NR (\%) \\
\hline Land & +91.1 & -44.4 & -44.1 & 2.6 & 2.85 \\
\hline Ocean & +142.8 & -124.3 & -11.0 & 7.5 & 5.25 \\
\hline
\end{tabular}

ECMWF (Brankovic and Molteni 1997), also show smaller values than Legates and Willmott in the secondary maximum related to the DJF SH storm track. As pointed out by Brankovic and Molteni (1997), the observational data of Legates and Willmot can have some errors at high latitudes in the Southern Hemisphere, related to lack of information. The maximum tropical precipitation of CPTEC-COLA AGCM in JJA is close to the values of Legates and Willmot and CMAP data (Fig. 1b).

The equatorial trough is simulated well in the zonal mean sea level pressure (SLP) (Figs. 1c,d) as well as the subtropical highs and the low pressure around $60^{\circ}$ in both hemispheres. The model estimates higher SLP in the Tropics and subtropics, irrespective of the season and hemisphere, but the differences are small except in the NH polar region. Although the SLP in the reanalysis data display differences from data at some stations in Antarctica (Hines et al. 2000), the zonally averaged low pressure around Antarctica in the region of storm tracks is similar to the reanalysis in both seasons.

The zonally averaged zonal wind field at $200 \mathrm{hPa}$ is shown in Figs. 1e,f for DJF and JJA, respectively. A reasonably good simulation of the overall circulation structure and the seasonal shifts of the maxima and minima is noticed, which is a reflection of the model's success in simulating the mean meridional tropospheric temperature gradients (see Fig. 3). In JJA, the model reproduces very well the intensity of the westerlies in the $\mathrm{NH}$ and shows values close to the observations in the $\mathrm{SH}$ and in the region of the tropical easterlies. In DJF the model overestimates in comparison with the NCEP-NCAR reanalysis values in the jet region of the $\mathrm{SH}$ and in the region of tropical easterlies. In the $\mathrm{NH}$, the model jet stream is shifted poleward with small differences in intensity in comparison with NCEP-NCAR reanalysis.

\section{c. Mean vertical structure of zonal wind and temperature}

DJF and JJA vertical structures of mean zonal wind from model results and from observations are shown in Figs. 2a-f. The jet streams in the model results are stronger than in the reanalysis dataset in both seasons of the two hemispheres, except in the NH (JJA) when the model reproduces very well the intensity and position of the subtropical jet. The jet stream centers in the model results are located around the level of $200 \mathrm{hPa}$ as in the reanalysis, but they are displaced southward in the $\mathrm{SH}$ when compared with the reanalysis. The occurrence of two jets in the SH winter (JJA), one subtropical and the other in the stratosphere at extratropical latitudes, is depicted by the model. Overall, the differences are larger in the mid- and high troposphere in both hemispheres and in the stratosphere of the SH as noted in Figs. 2c,f.

The general vertical structure of the zonal mean temperature in the model results is comparable to the reanalysis structure (Figs. 3a-f). The seasonal variations in the lower troposphere are depicted well in both hemispheres. The vertical structure of temperature is simulated well in the Tropics and subtropics of the Northern and Southern Hemisphere in both seasons. However, there are differences between the model and reanalysis, mainly at mid- and upper levels at mid- and high latitudes, indicating a cold bias in the troposphere (Figs. $3 c, f)$. There are large differences over the Antarctic region at high levels and in the stratosphere that extend to the midlatitudes, with a cold bias in these areas. As mentioned earlier, the reanalyses data can contain some errors near Antarctica, and the bias may not reflect model error. Cold bias is also found in other models such as ECMWF and was reduced in that model by introducing changes in radiation and cloud parameterization and by increasing the vertical resolution (Brankovic and Molteni 1997). However, these changes introduced a warm bias in the tropical stratosphere.

The differences are smaller in JJA than in DJF in the upper levels of the polar latitudes and midlatitudes of $\mathrm{SH}$ but are larger in the upper levels of the polar regions of NH. In the global stratosphere there are large errors in both seasons.

\section{d. Seasonal precipitation}

The main features of the seasonal cycle of precipitation are well represented, as shown in Figs. $4 a-1$. The displacement of the Atlantic ITCZ southward in DJF and March-April-May (MAM) and northward in JJA and September-October-November (SON) is depicted well by the model. The model overestimates the precipitation values in the Atlantic ITCZ, and, except in DJF, the differences tend to be large close to the South American and African coasts. The precipitation of the Pacific ITCZ is also overestimated, with larger differences over the eastern Pacific, close to Central America. Over the western Pacific, the errors are related to the northward shift of the ITCZ.

The model shows correctly the three bands of precipitation related to the South Atlantic convergence zone (SACZ), the South Pacific convergence zone (SPCZ), and the South Indian convergence zone (SICZ) in DJF. Excessive precipitation is simulated in the southern sectors of the SACZ and SICZ, and underestimated values are found to the west-northwest of these areas. In the 
a)

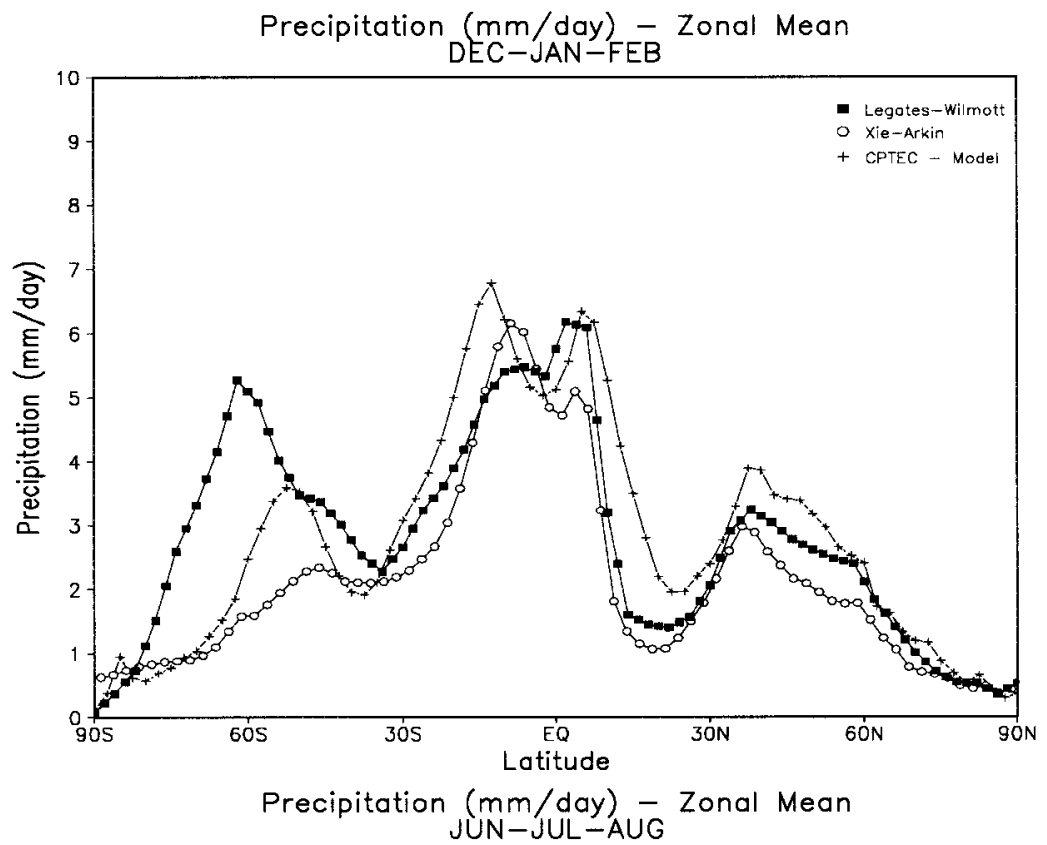

b)

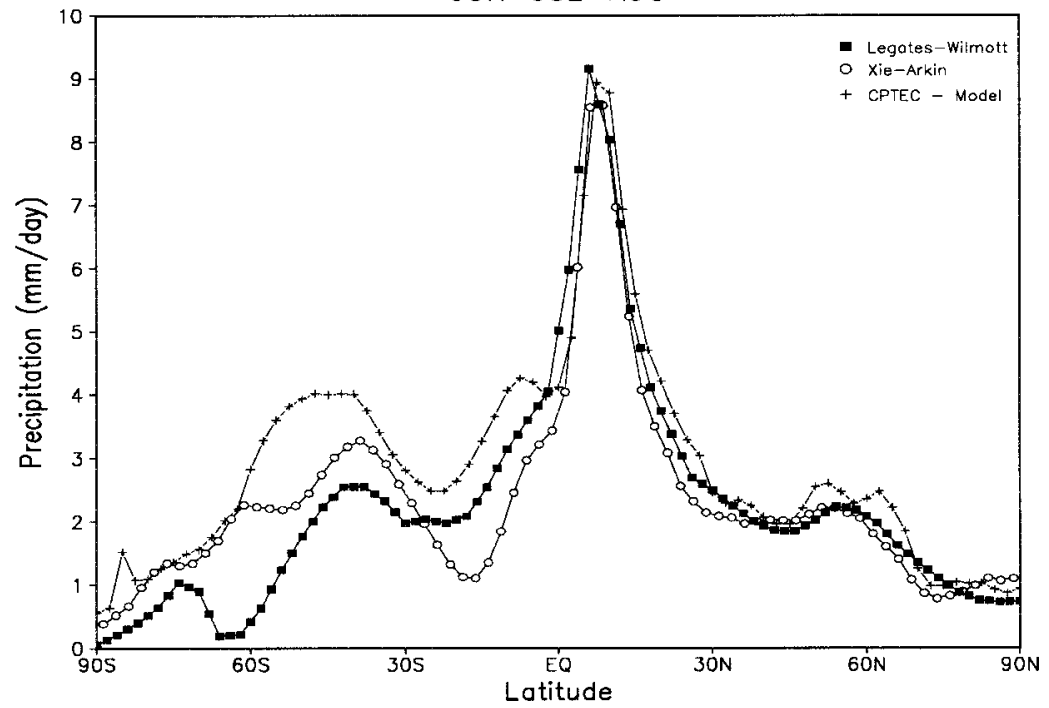

FIG. 1. Zonal mean precipitation: (a) DJF, (b) JJA; pressure: (c) DJF, (d) JJA; zonal wind at $200 \mathrm{hPa}$ : (e) DJF, (f) JJA for the ensemble mean and observed data. Observed precipitation (mm day $^{-1}$ ) is from Legates and Willmot (1990) and CMAP (Xie and Arkin 1997). Observed pressure $(\mathrm{hPa})$ and wind fields $\left(\mathrm{m} \mathrm{s}^{-1}\right)$ are taken from NCEP-NCAR reanalysis data.

SPCZ, the errors are due to the different orientation of the precipitation band, which is NW-SE during this season in the observations but is almost zonal in the model simulation.

Common differences over South America in almost all seasons are the excessive precipitation over northeastern, eastern, and extreme southern parts of the continent, over the Andes Cordillera, and the deficiency of precipitation over Amazonia, and central and southeastern South America (Figs. 4c,f,i,l). The overestimation over the Andes is related to the deficiency of the spectral representation of the orography and the as- sociated circulation. The spurious precipitation anomaly in this region was also found by Stern and Miyakoda (1995), who mention the Gibbs error associated with truncation of steep orography. In JJA, when the humidity is very low over central South America, the model does not produce heavy precipitation over the mountain and simulates the low precipitation values observed over most of the continent in this season (Figs. 4g,h,i).

The excessive precipitation in the eastern Pacific ITCZ and in the southern part of SACZ may contribute to the deficiency of model rainfall over Amazonia. Conceptual models of the effect of compensating subsidence 


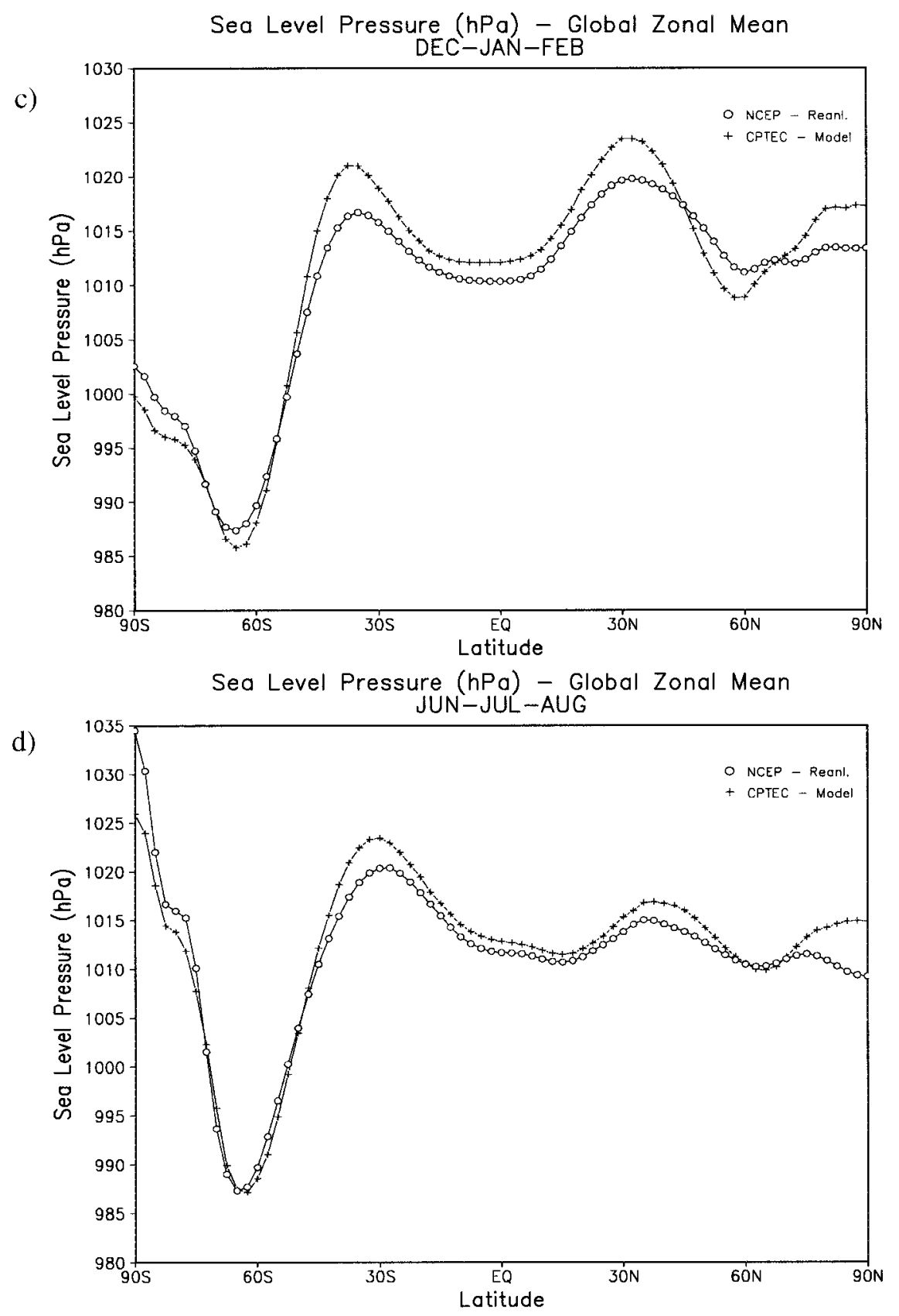

FIG. 1. (Continued)

associated with tropical heat sources corroborate the coupling between the convection in the SACZ and Amazon (Gandu and Silva Dias 1998). This same kind of error over the Amazon region was also found in other GCMs, such as ECMWF (Brankovic and Molteni 1997), NCAR CCM3 (Hurrell et al. 1998), and the Geophysical Fluid Dynamics Laboratory (Stern and Miyakoda 1995). When the RAS scheme for deep convection was used instead of the Kuo scheme in the COLA version of the global spectral model (Shukla et al. 2000b) and in the CPTEC-COLA version (Pezzi and Cavalcanti 2000), precipitation errors were very different over Amazonia. The RAS scheme provided higher precipitation over Amazonia and reduced the values in the southern portion of the SACZ, when compared with the Kuo scheme, but the errors were much higher, and there was an unrealistic dry area to the north of the maximum values in the Amazon (Pezzi and Cavalcanti 2000). The relationship between parameterization schemes and model response is discussed in section 6 .

HadCM3 (Johns et al. 1997), which is a coupled atmosphere-ocean model and uses a mass flux penetrative 
$200 \mathrm{hPa}$ Zonal Wind $(\mathrm{m} / \mathrm{s})$ - Global Zonal Mean

DEC-JAN-FEB

e)
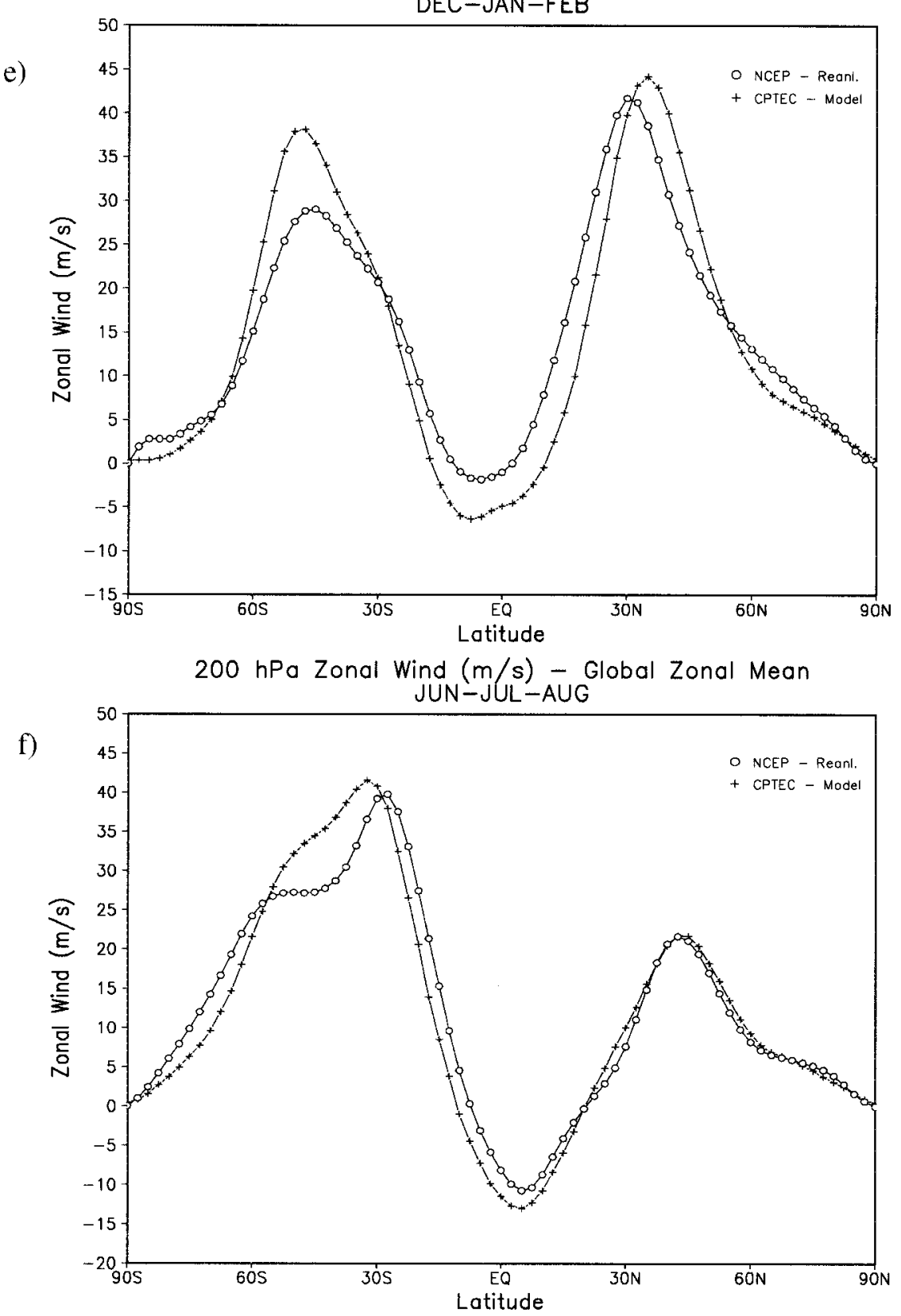

Fig. 1. (Continued)

convection scheme (Gregory and Rowntree 1990), produced DJF precipitation over Amazonia that was closer to observations than that of other models, including the CPTEC-COLA. This scheme considers a single cloud model with different cloud characteristics, and the magnitude of convective activity is calculated by considering the stability of the lowest convective layer only (Gregory and Rowntree 1990). The difference of results obtained by the other models, which use Kuo or Arakawa-Schubert, may be related to the fact that these models are based on large-scale moisture convergence or assume a quasi-equilibrium state between convection and large-scale forcing, requiring also large-scale convergence to be present before the process of convection be initiated, whereas the scheme used at the Hadley Centre only requires positive buoyancy to initiate the convective process. It seems that, considering the largescale moisture convergence, excess of precipitation is concentrated in some regions, and this condition affects the spatial distribution of rainfall. Improvements of the precipitation rates over Amazonia were also shown in model experiments of Marengo et al. (1993), changing 
DJF
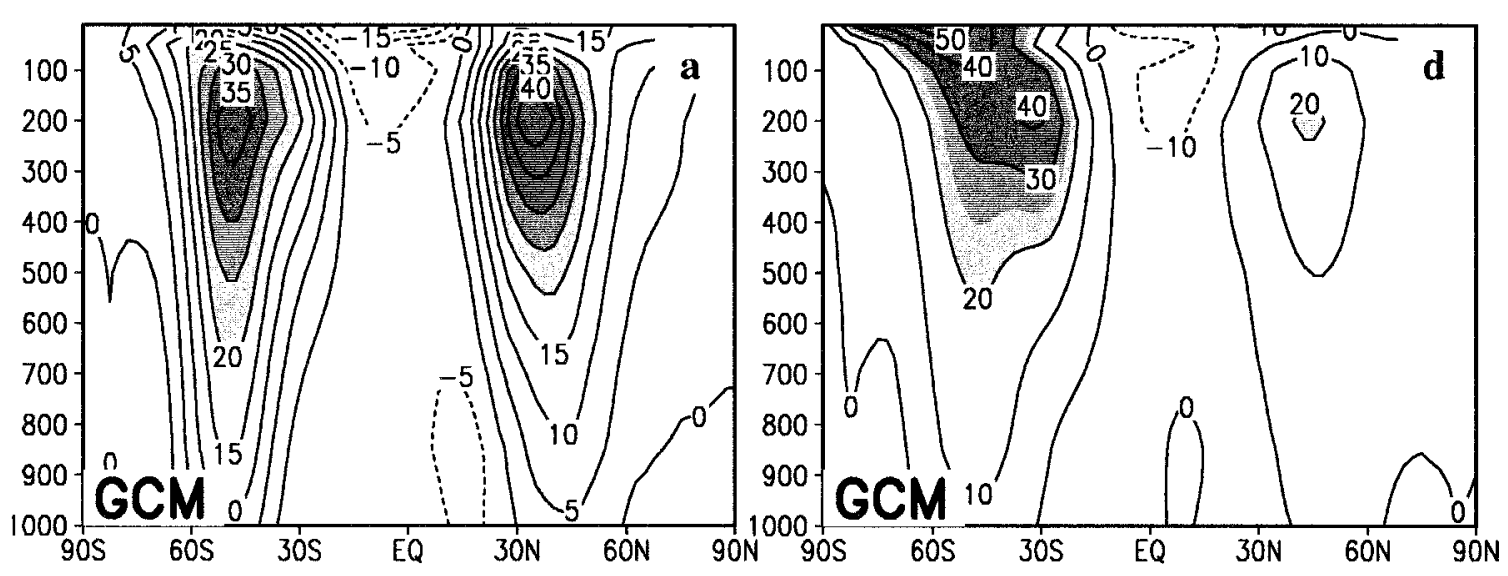

JJA
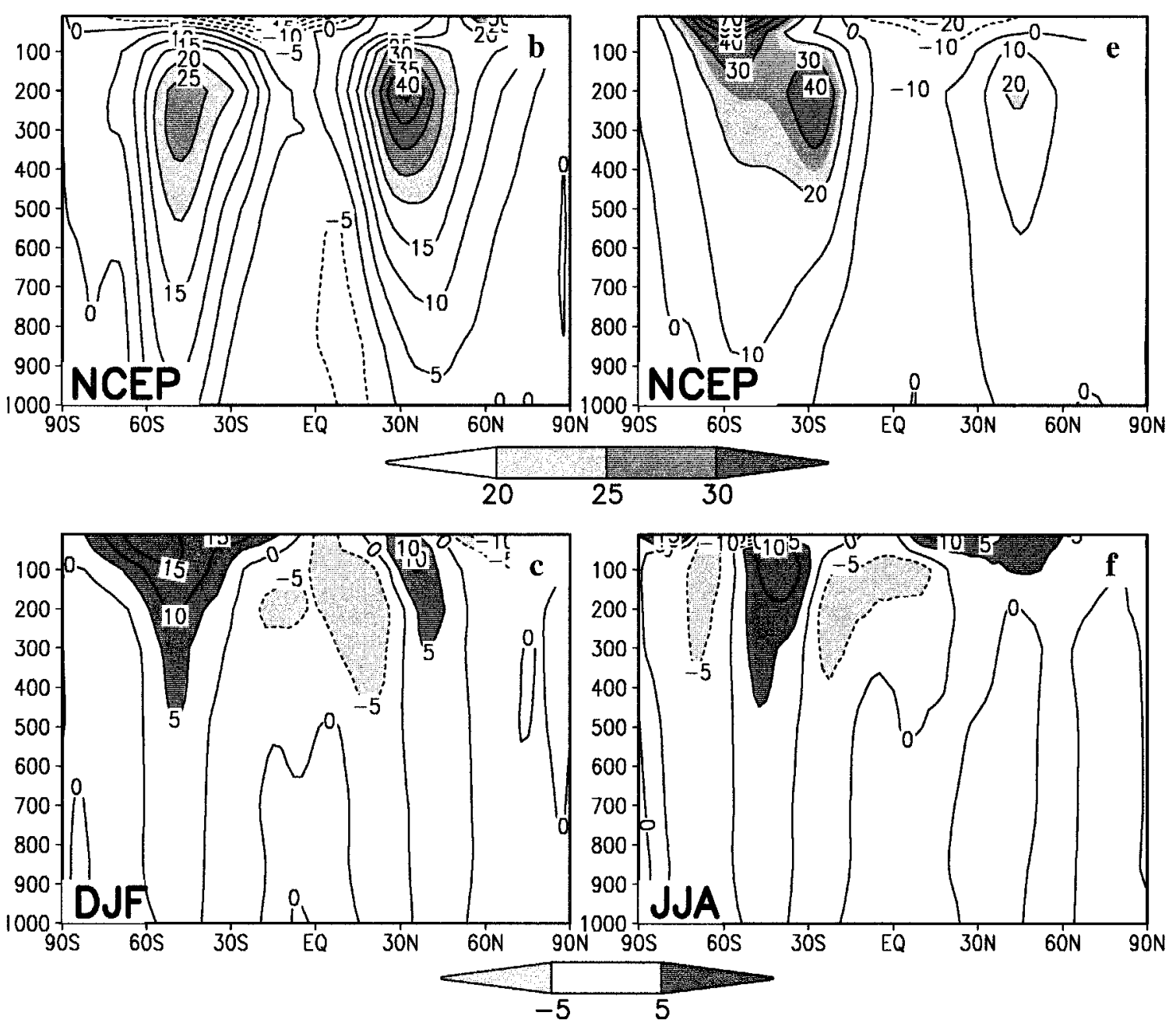

FIG. 2. Climatological vertical structure of zonal wind ( $\mathrm{m} \mathrm{s}^{-1}$ ): DJF (a) CPTEC-COLA AGCM and (b) NCEP-NCAR reanalysis, and JJA (d) CPTEC-COLA AGCM and (e) NCEP-NCAR reanalysis. (c), (f) The differences between the model and observations. 

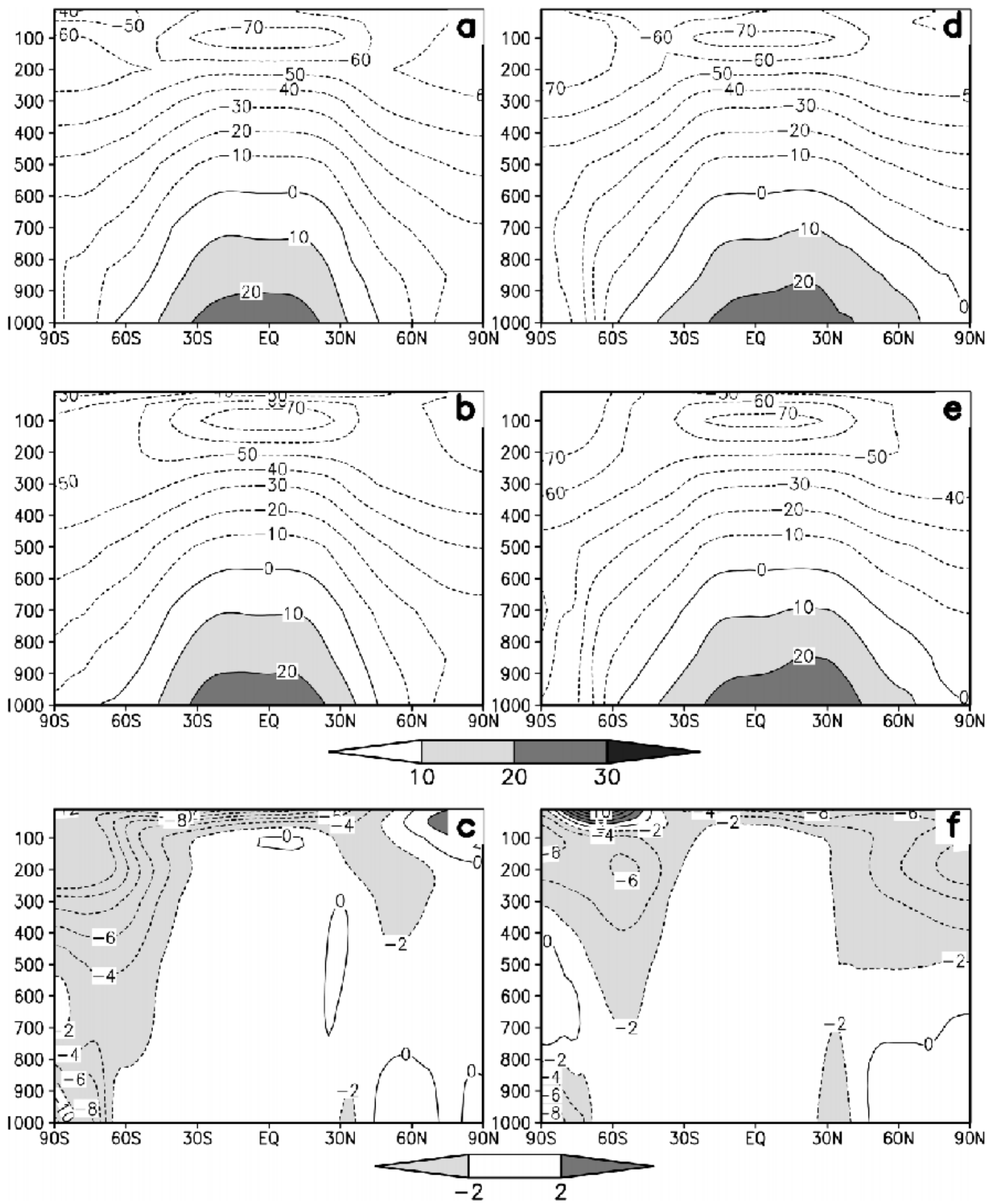

FIG. 3. Same as Fig. 2 but for air temperature $\left({ }^{\circ} \mathrm{C}\right)$.

the ground hydrological scheme in the Goddard Institute for Space Studies GCM.

The systematic errors over northeast Brazil (Nordeste) occur also in all seasons, but the most relevant is in MAM, which is the rainy season of this region. The model captures the influence of the ITCZ, which is located in the southernmost position, but continues to represent a NW-SE band of precipitation similar to the SACZ, extending from Nordeste to the Atlantic Ocean, linked to the ITCZ and to the convection over the Am- 
azon region, a feature that does not exist in CMAP (Figs. $4 \mathrm{~d}, \mathrm{e})$. In the observations, the band of precipitation NW-SE is located over southern Brazil and is associated with the presence of frontal systems in that region. The model also shows a tilting of the ITCZ toward NE that gives an overestimation of precipitation in parts of the semiarid region and an underestimation at the mouth of the Amazon River (Fig. 4f). In SON, the convection over Amazonia extends again southeastward in both model results and CMAP data, but less so over central South America in the model results than in the observational dataset. Over southeastern Brazil, precipitation is also overestimated (Figs. 4j,k,1). The underestimated precipitation over southeastern South America in all seasons may be related to the displacement of the storm tracks southward in the model, a feature that is observed in the difference fields and that extends over the extratropical latitudes of the Southern Hemisphere.

Other systematic errors occur in the tropical regions in all seasons. In the Indonesia region, precipitation is underestimated over the northern region and is overestimated to the north and south. This feature is associated with the displacement of the ITCZ. There are also some differences related to the intensity of precipitation in the southeastern part of the SPCZ. In the Indian monsoon region, seasonal precipitation variability is simulated well by the model, with maximum precipitation in JJA, although with overestimated values in the southern area and underestimated values in the northern area. In this study, rain rates of up to $1 \mathrm{~mm} \mathrm{day}^{-1}$ are simulated well over Australia and over the subtropical highs. This is a distinct feature seen in these model results, different from the deficiency of light rains found in the intercomparison project models (Lau et al. 1996).

The model also overestimates the values in all seasons over tropical and southeastern Africa. However, the seasonal variability is simulated well over Africa, where there is more intense precipitation in DJF. In tropical Africa, the shift of the convection southward in DJF and northward in JJA is noticeable. The precipitation is also overestimated over Asia and Europe. Over many areas of North America, the model underestimates precipitation in JJA and SON and overestimates precipitation in DJF and MAM. Over the North Atlantic and North Pacific, precipitation associated with the storm tracks is identified in the model results, mainly in the winter season, DJF; however, CMAP shows smaller values.

\section{e. Sea level pressure and low-level winds}

The subtropical Pacific and Atlantic high pressure centers are reproduced in both hemispheres in the sea level pressure fields (Figs. 5a-f), although in the SH the intensity is higher in DJF in the model results than in the NCEP-NCAR reanalysis data. In general, the pressure in the model is higher than in the reanalysis over most of the globe except at high latitudes of both hemispheres, where it is lower. An exception is the positive bias over
Greenland. Low pressure over South America, South Africa, and the Indonesia region are noticed in DJF (austral summer) and in northeast Asia in JJA (boreal summer), associated with surface heating. Low pressure is replaced by high pressure in the respective winter seasons in these regions, features seen in model results and reanalysis data. The highest and most persistent errors in the $\mathrm{SH}$ surface pressure are found southeast of the AustraliaNew Zealand region. In the NH, the largest errors occur over Greenland and Europe in DJF (Fig. 5c). Because these regions are regions of blocking situations, the model apparently enhances blocking in the North Atlantic and weakens blocking in the Australian region.

The near-surface flow $(850 \mathrm{hPa})$ over the oceans (Figs. 6a-f) shows the circulation associated with the subtropical highs. The general seasonal characteristics of the subtropical highs are represented well by the model; for example, the largest influence of the South Atlantic high (SAH) over South America is in winter, when the circulation center is closer to the continent. The seasonal changes, which are simulated well by the model, have implications on the precipitation of some regions, as in the north part of the northeast region of South America. The southeastward displacement of the SAH in DJF and the change in the direction of the trade winds in the tropical region are related to the southward displacement of the tropical confluence zone, which has an influence on the position of the ITCZ. In JJA, the winds are almost parallel to the north coast of Brazil; in other seasons they have a strong onshore component.

The Indian monsoon circulation is captured by the model, which shows similar features to those displayed in the reanalysis data, with the southwesterly flow in JJA. In DJF, there are reversed winds over the region in model and reanalysis fields. The anticyclonic circulation over Australia is represented well in all seasons except DJF, for which season the model has easterly flow over the country while the reanalysis data show easterlies concentrated over the northern region. The differences between the model and reanalysis data (Figs. $6 \mathrm{c}, \mathrm{f})$ show that the Atlantic and Pacific trade winds are weaker in the model than in the reanalysis.

\section{f. Upper-level flow}

The model wind field at $200 \mathrm{hPa}$ shows the main global climatological features, such as the stronger wintertime subtropical jet streams and anticyclonic circulations associated with summertime deep convection (Figs. 7a-f). The subtropical jets are stronger in the winter hemisphere, and their longitudinal locations are simulated well by the model. However, they are displaced slightly poleward. In the NH the jet streaks are situated to the east of Asia, North America, and North Africa. The model results show the North Atlantic jet to be stronger and the North African jet to be weaker than in the reanalysis. In the SH, the winter (JJA) Aus- 
DJF
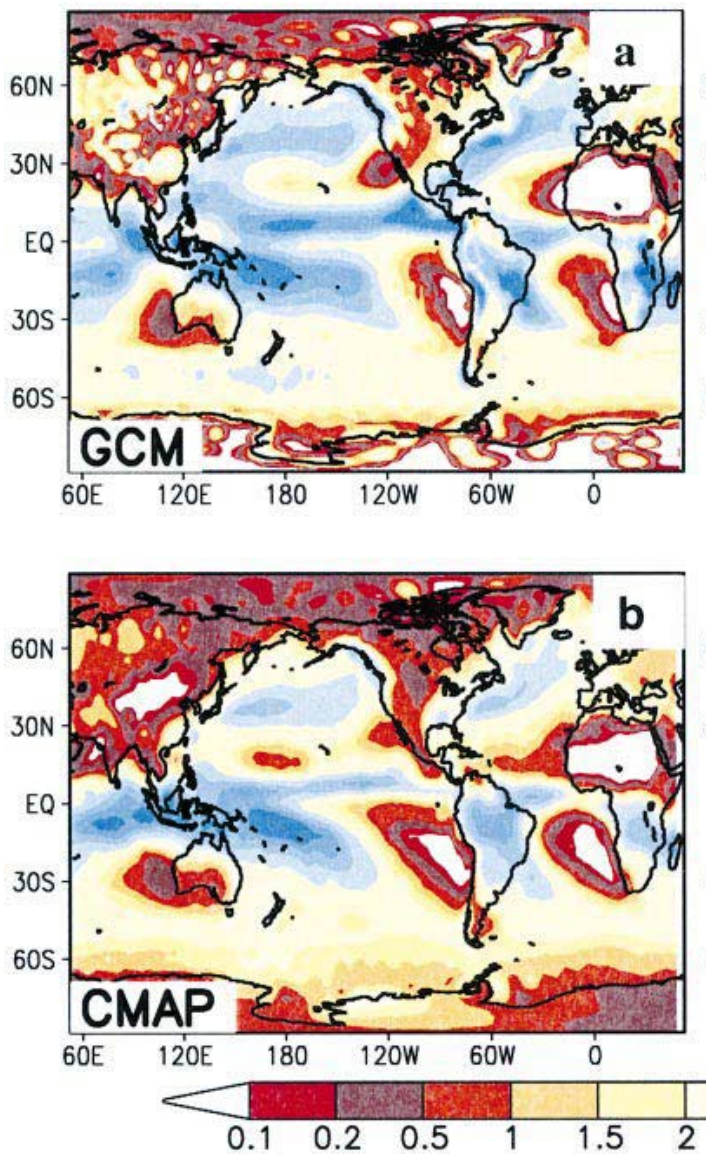

MAM
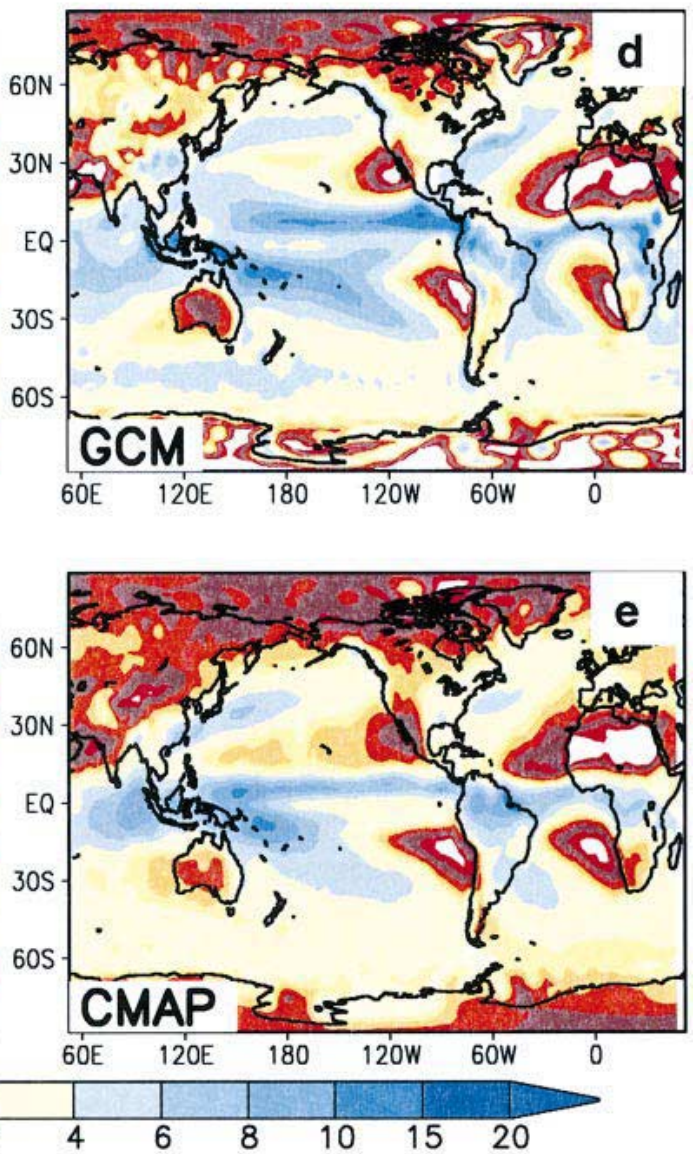
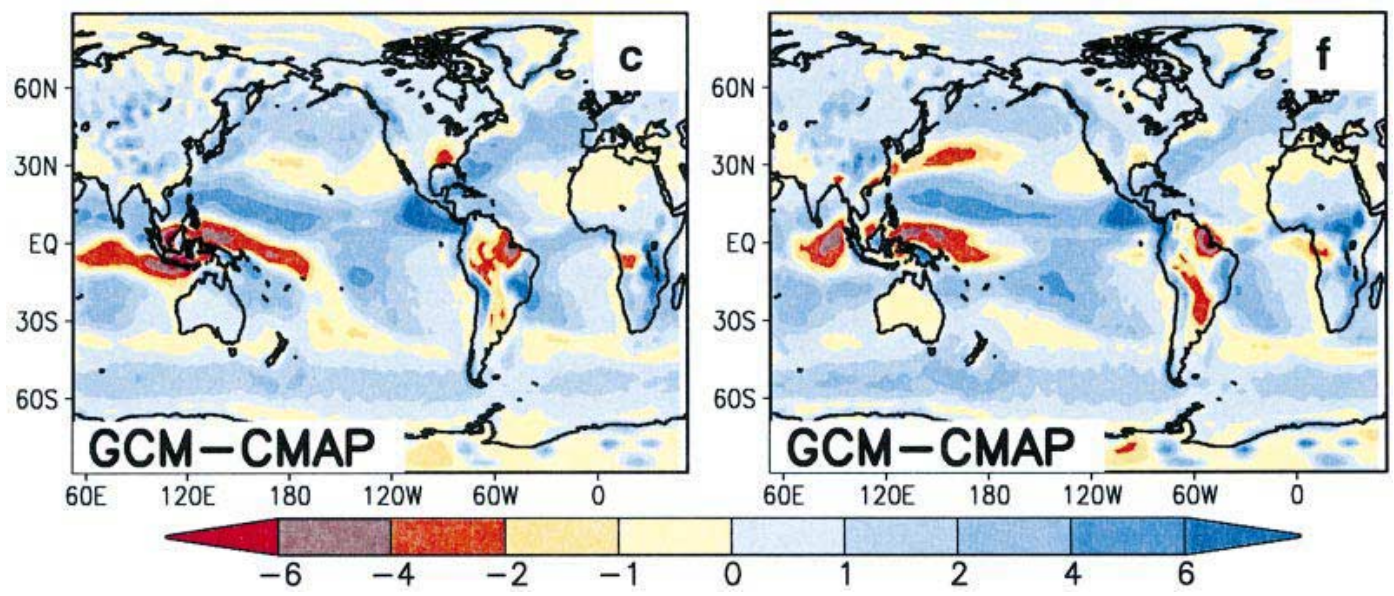

FIG. 4. Climatological precipitation ( $\mathrm{mm} \mathrm{day}^{-1}$ ): (a) DJF CPTEC-COLA AGCM, (b) DJF CMAP, (d) MAM CPTECCOLA AGCM, (e) MAM CMAP, (g) JJA CPTEC-COLA AGCM, (h) JJA CMAP, (j) SON CPTEC-COLA AGCM, and (k) SON CMAP. (c), (f), (i), (l) The differences between model and observations.

tralian jet does not extend over Australia, as it does in the reanalysis, so it affects a smaller area.

The anticyclonic circulation centers over South America, South Africa, and the western Pacific region in DJF are associated with the summer convection in the Southern Hemisphere. The anticyclonic circulation over the Tibet region in JJA is associated with the monsoonal heating in that region. In the difference fields, the anticyclonic circulation over southern Asia indicates that the heat source is overestimated by the model over the Tibetan Plateau.

The main differences between the model and reanal- 
JJA
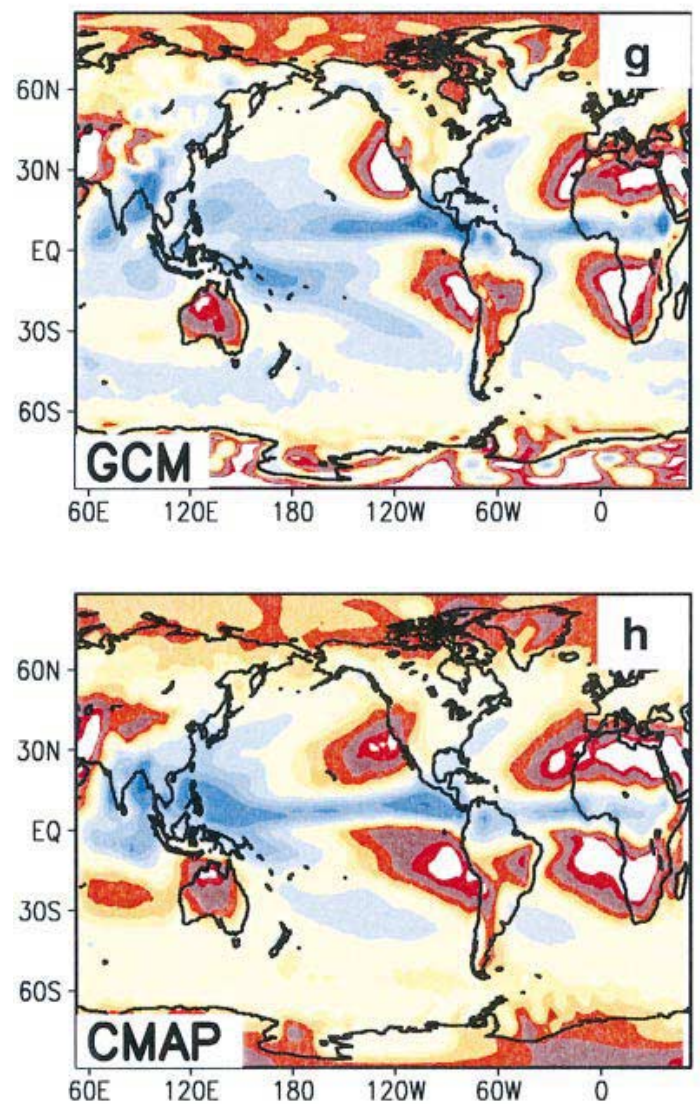

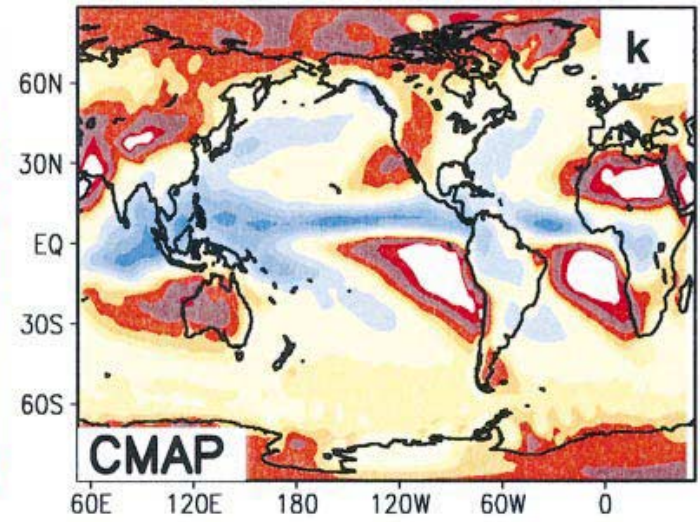

SON
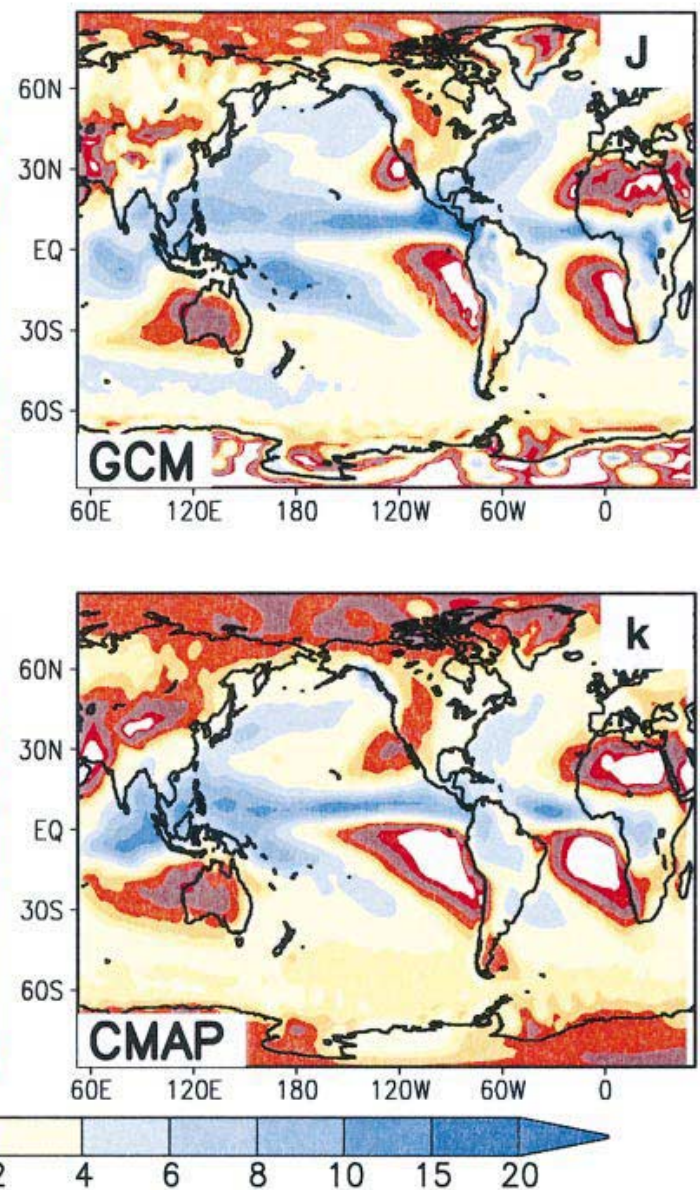

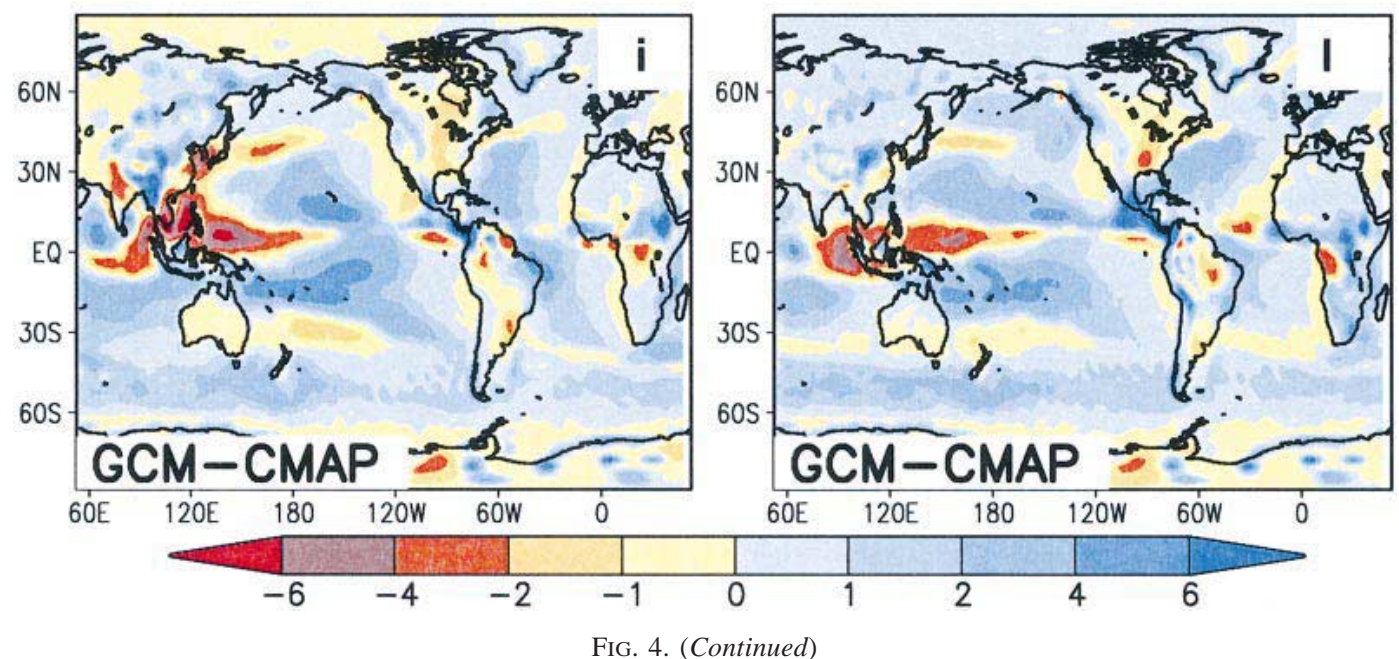

ysis over South America are related to the position and intensity of the anticyclonic circulation. The deficit of precipitation over the Amazon region and excess over the Andes can have an implication on the position and intensity of the anticyclonic circulation at high levels over South America in the Southern Hemisphere sum- mer. In the reanalysis, the Bolivian high is concentrated over western South America; in the model results, it is displaced southwestward over the mountain and extends in the west-east direction. The cyclonic circulation seen in the difference field, over Amazonia, means less intense anticyclonic circulation in the model results than 
DJF
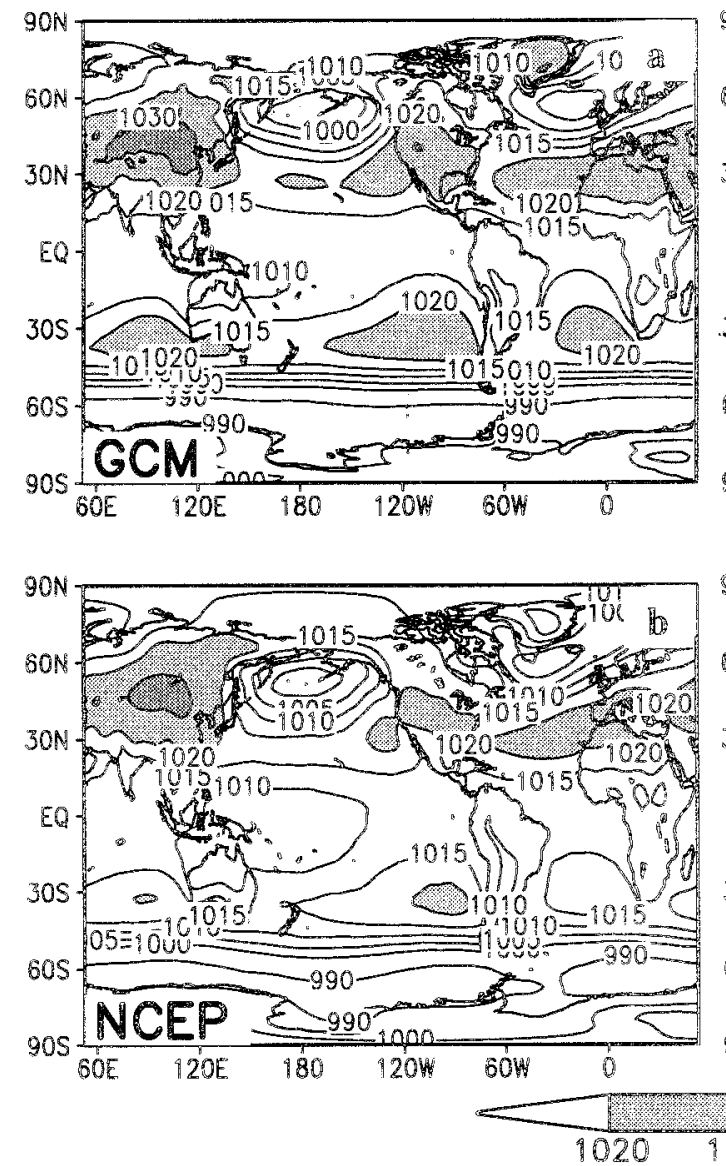
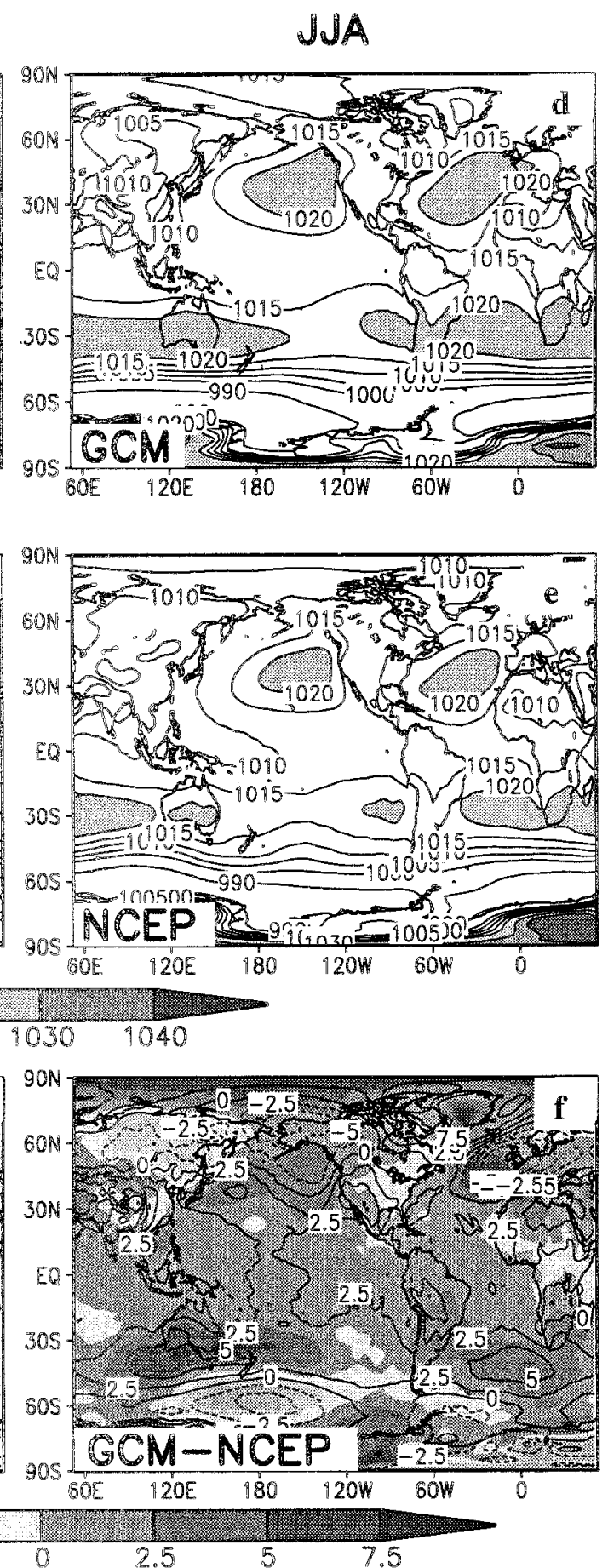

FIG. 5. Climatological sea surface pressure (hPa): DJF (a) CPTEC-COLA AGCM and (b) NCEP-NCAR reanalysis, and JJA (d) CPTEC-COLA AGCM and (e) NCEP-NCAR reanalysis. (c), (f) The differences between the model and observations.

in the reanalysis. This result could be associated with weaker divergence at high levels in the model simulation. The anticyclonic circulation to the east of South America in the difference field can be a result of the SACZ enhancement in the model results, affecting also the Atlantic trough configuration.

\section{g. Geopotential zonal anomalies}

The zonal means are removed from geopotential fields to enhance the stationary climatological features, which are shown in Figs. 8a-f, at $200 \mathrm{hPa}$, for the Northern Hemisphere and in Figs. 9a-f for the Southern Hemi- 

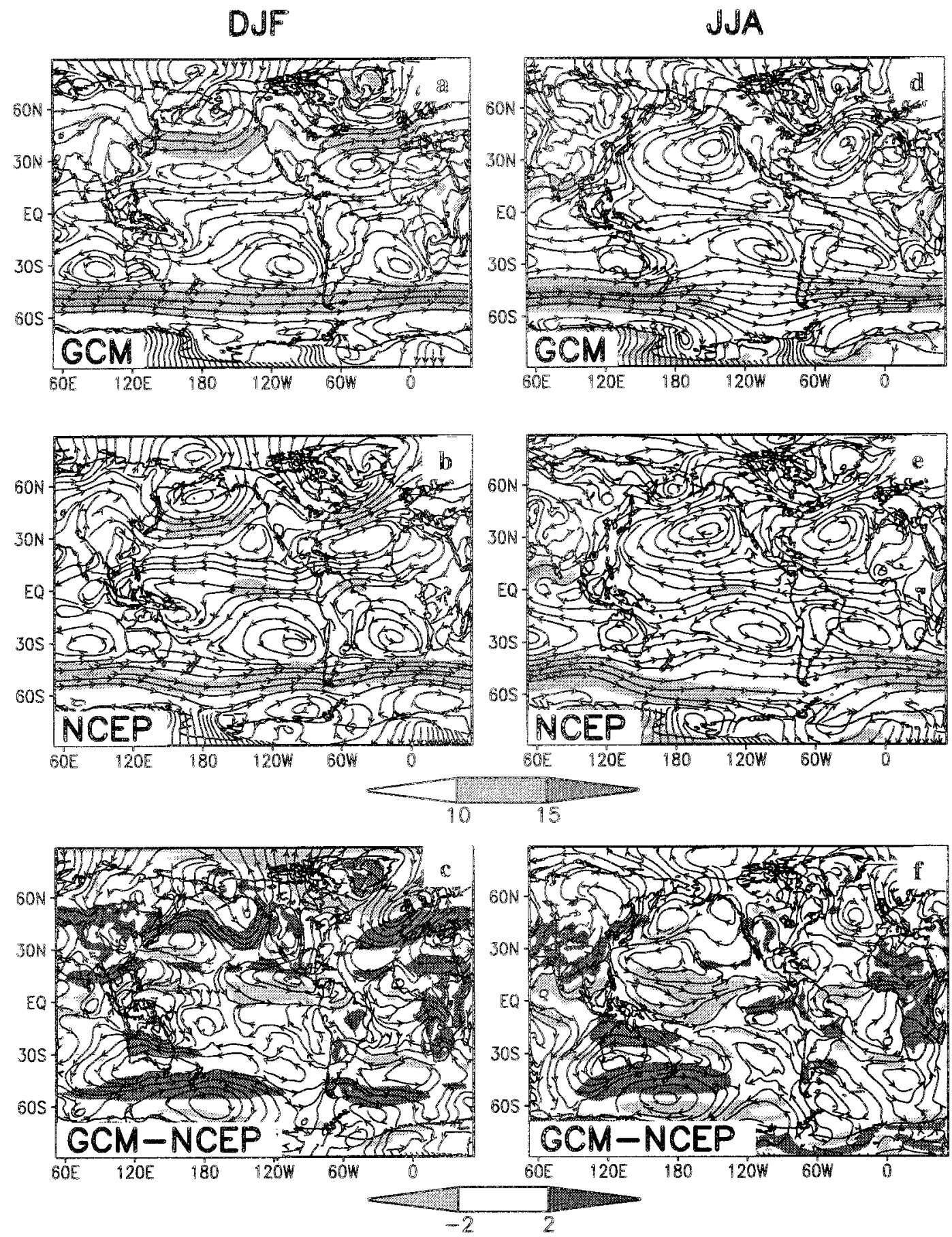

FIG. 6. Isolines and magnitude of climatological wind field at $850 \mathrm{hPa}\left(\mathrm{m} \mathrm{s}^{-1}\right)$ : DJF (a) CPTEC-COLA AGCM and (b) NCEP-NCAR reanalysis, and JJA (d) CPTEC-COLA AGCM, and (e) NCEP-NCAR reanalysis. (c), (f) The differences between the model and observations. The magnitudes are shaded.

sphere. In DJF, the model reproduces the dominance of wavenumber 2 , with two troughs and two ridges, a characteristic feature of the $\mathrm{NH}$ winter at mid- and high latitudes. The stationary troughs and ridges are reproduced with some differences in intensity and position. The ridge over the subtropical Pacific and the trough over North Africa, featuring a wavenumber 1 in the subtropics, are simulated, although the trough is less intense in the model results than in the reanalysis.

In JJA, the wave train extending from the western Pacific Ocean over North America to the North Atlantic Ocean is reproduced, and the position and intensity of 

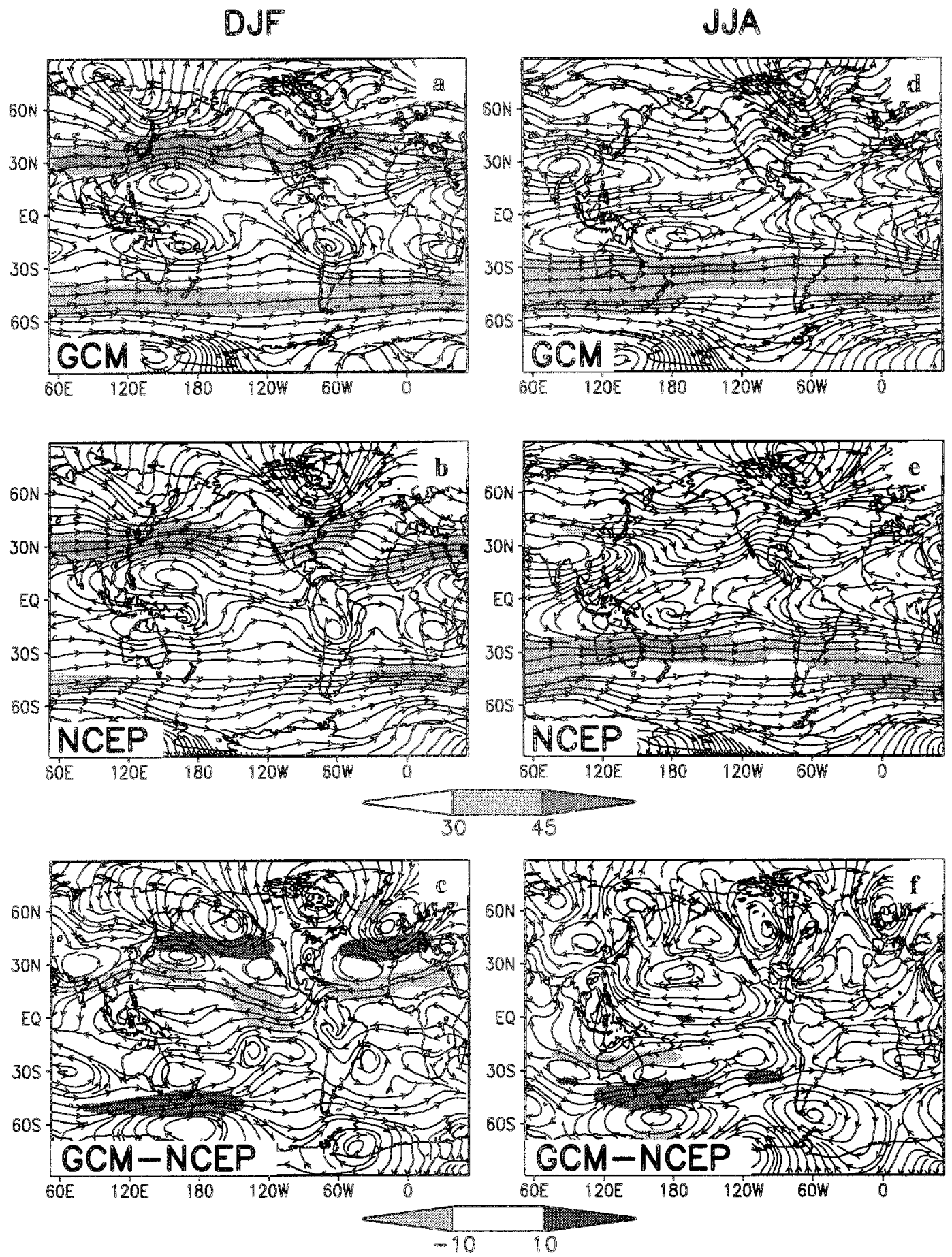

Fig. 7. Same as Fig. 6 but at $200 \mathrm{hPa}$.

the Tibetan high are simulated well. The intense ridge is related to the strong heating and convection in that region during the $\mathrm{NH}$ summer season. These $\mathrm{NH}$ winter and summer patterns are also represented in the climatological geopotential analyses at $200 \mathrm{hPa}$, as discussed in Wallace (1983). Similar patterns for mid- and high latitudes are seen at $500 \mathrm{hPa}$ (not shown). At this level, the model represents well the reduction of the zonal anomalies and the suppression of the high-level subtropical features.

In the Southern Hemisphere, the wavenumber 1 observed in the reanalysis in DJF and JJA is reproduced in the model results, but there are some differences related to the intensity and position of zonal anomaly centers. 

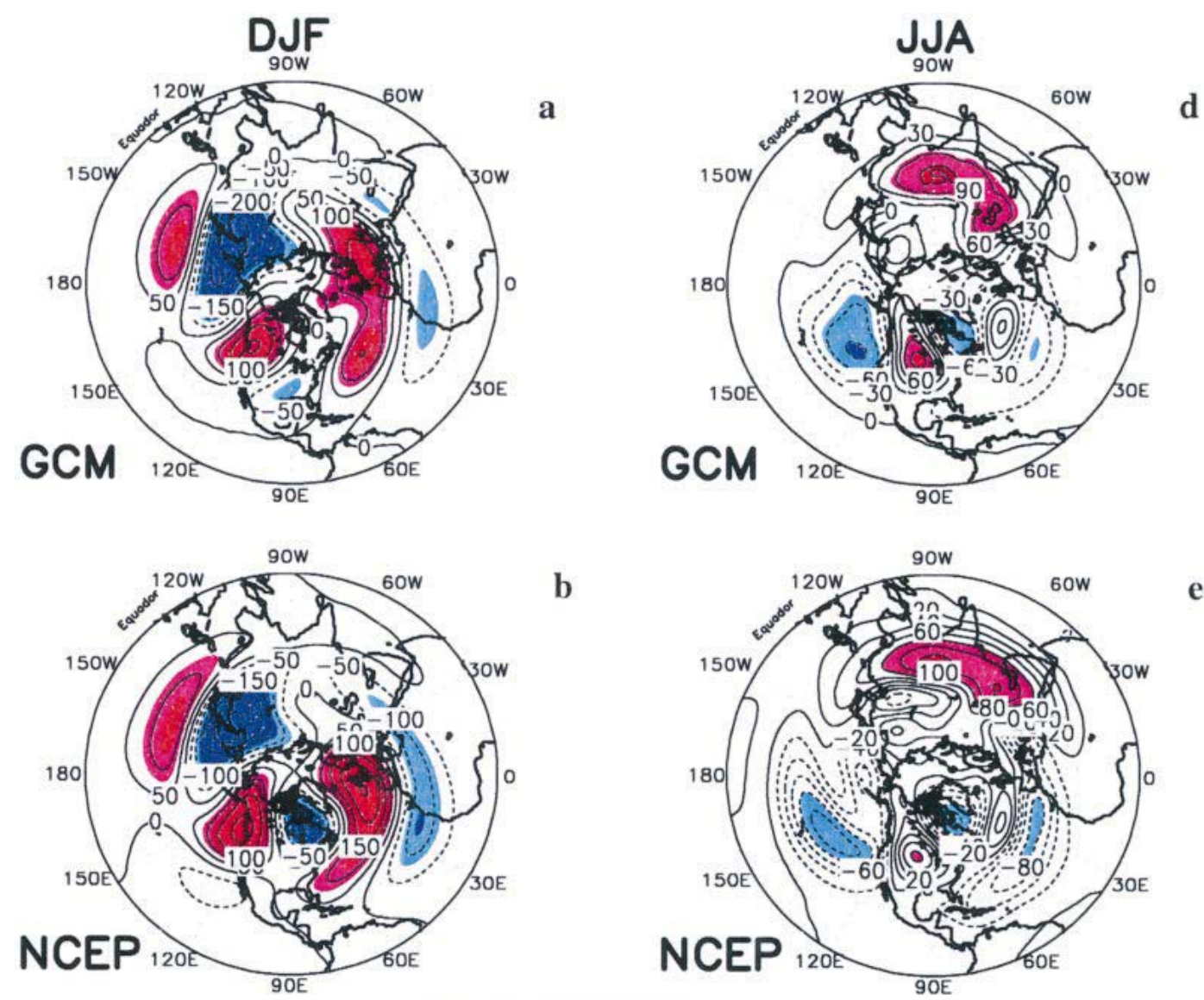

b
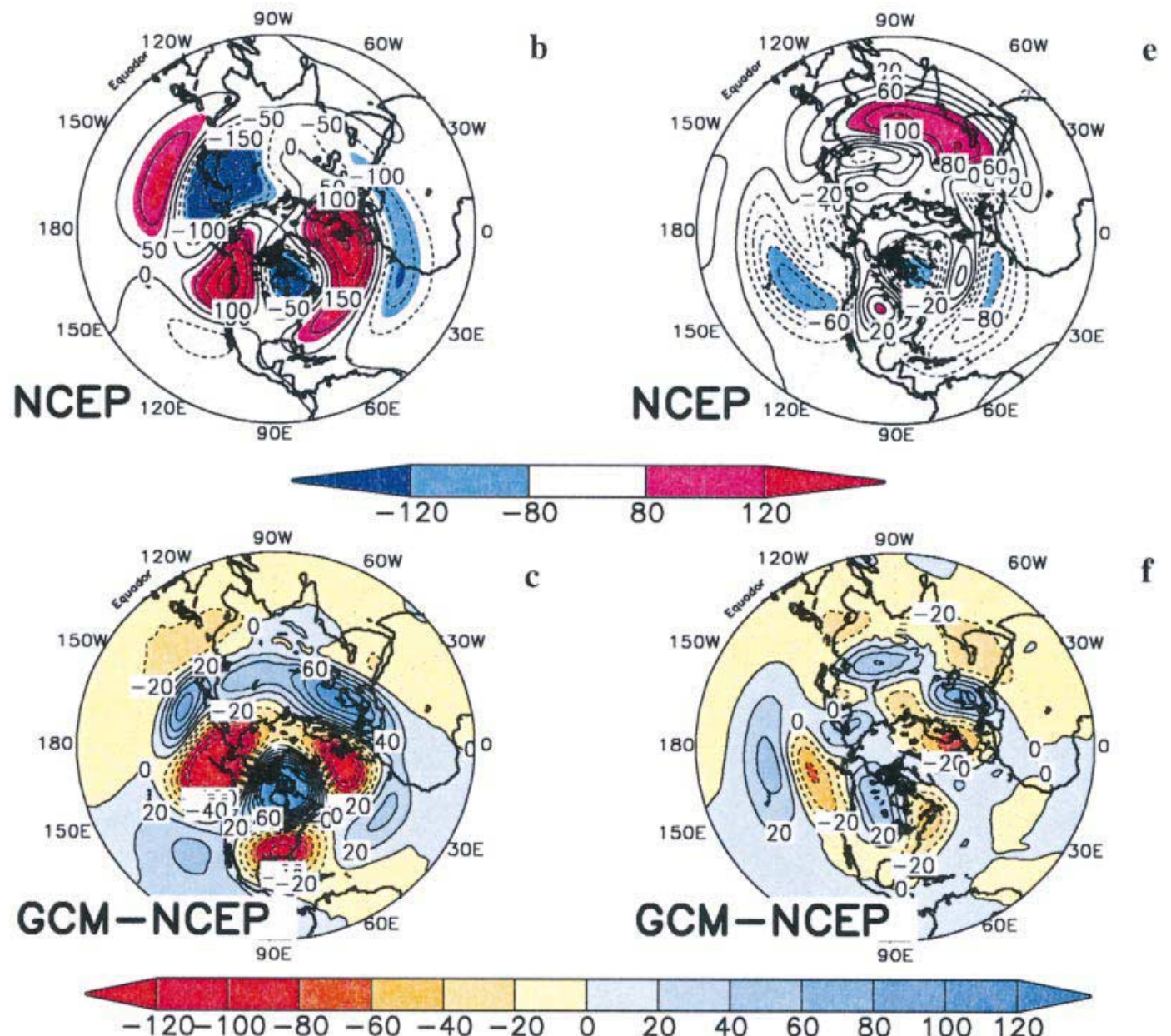

FIG. 8. Climatological zonal geopotential height anomaly (m) at $200 \mathrm{hPa}$ for the Northern Hemisphere: DJF (a) CPTEC-COLA AGCM and (b) NCEP-NCAR reanalysis, and JJA (d) CPTEC-COLA AGCM and (e) NCEP-NCAR reanalysis. (c), (f) The differences between the model and observations.

The anomalous centers at mid- and high latitudes are weaker in the model than in the reanalysis, representing the weaker amplitude of the stationary wave in the model. The ridge over the South Pacific is shifted eastward in DJF when compared with the reanalysis, but in JJA the maximum center close to the Antarctica Peninsula is in the right position. In this region, the ocurrence of blocking situations is frequent, as analyzed by Marques and Rao (1999) and Renwick (1998). The ability of the model in representing well the positive geopotential anomaly 
may indicate that the model is able to simulate blocking occurrences. At subtropical latitudes, the wavenumber 1 has the opposite sign to that at high latitudes and the model presents similar intensities to the reanalysis in DJF but slightly displaced eastward. In fact, the whole model pattern is shifted eastward, showing larger displacement in the South Pacific ridge.

The differences between the model and reanalysis fields of geopotential zonal anomaly in both hemispheres are shown in Figs. 8c,f and Figs. 9c,f. At the high latitudes of the $\mathrm{SH}$, the errors occur at the same regions in both DJF and JJA. At subtropical latitudes, the largest errors occur over the eastern and western South Pacific in DJF, and they extend over South America and over southern Australia in JJA. In the NH, the errors are larger in DJF, related to the shifting and intensity of the ridges and troughs. Because the atmospheric stationary waves are in part related to orography, the errors in intensity and position of the main centers of the stationary features may be associated with the poor representation of the model topography.

\section{El Niño-Southern Oscillation features in the model simulation}

The Southern Oscillation index (SOI) is calculated from the model results following the methodology performed by the NCEP Climate Prediction Center. The SOI is calculated by first computing the difference (Tahiti minus Darwin) in the standardized sea surface pressure. This result is then standardized by the standard deviation of the time series of differences to arrive at the SOI.

The interannual variability of the SOI shows that the major interannual fluctuations, including the 1982/83 and 1986/87 El Niño and the 1984/85 and 1988/89 La Niña events, are reproduced well, with the model ensemble mean variation following closely the observed (Fig. 10). To test the sensitivity of rainfall response to ENSO conditions and to illustrate the response of the CPTEC-COLA AGCM equatorial rainfall, the timelongitude equatorial $\left(5^{\circ} \mathrm{S}-5^{\circ} \mathrm{N}\right)$ sections of rainfall from the CPTEC-COLA AGCM and the respective verification from CMAP are shown in Fig. 11. The model simulates the eastward migration of the rainfall from the western to the central Pacific during the 1982/83 and 1986/87 El Niño events. In general, the precipitation is overestimated in the tropical region; however, in this latitudinal band $\left(5^{\circ} \mathrm{S}-5^{\circ} \mathrm{N}\right)$, the model underestimates precipitation in some longitudes.

Large-scale forcing associated with tropical Pacific SST influences the large-scale general circulation and affects several areas of the globe. Simulations by other models have reproduced one of the dynamical responses to variations in tropical Pacific SST in the upper levels, that is, the Pacific-North American (PNA) pattern (Shukla et al. 2000a,b). For the differences between El Niño (1982/83) and La Niña (1988/89) DJF 500-hPa geopotential height, CPTEC-COLA AGCM simulates the pat- tern obtained from reanalysis data, although with weaker centers (Fig. 12). The ability of the model to reproduce the effects of ENSO on atmospheric circulation patterns is important to provide confidence in seasonal prediction of the regions affected during these episodes.

\section{Anomaly correlations and reproducibility}

Time correlation of seasonal anomalies between the ensemble mean model results and the observational CMAP dataset is presented in Figs. 13a-d. The systematic errors analyzed in the difference fields, section $3 \mathrm{c}$, showed the errors related to the precipitation values. These errors are partially removed in the correlation fields, which are related to the anomalies in each season of each year. The Student's $t$ test gives 95\% and 99\% confidence to correlations higher than 0.5 and 0.7 , respectively.

The correlation is high over the tropical Pacific and Atlantic Oceans, with very high values over the eastern Pacific Ocean. This result indicates that the precipitation variability in these regions is simulated well by the model. Although there are errors related to intensity or position of the Atlantic and Pacific ITCZ, the anomalies are well represented. The highest correlations over the tropical oceans indicate the ability of the model to respond to the local SST forcing. Over the extratropical regions the response is reduced, but several areas of these regions are seen with positive correlations.

The high seasonal predictability over northeast Brazil, discussed in other studies, such as Graham (1994) and Ward and Folland (1991), is also verified in the current analysis. The correlation over this region is above 0.5 in all seasons, and in MAM correlations of 0.7 extend to large areas of the northeast. This predictability is an important feature to rainfall prediction in this area, which has most of the rainy season in MAM. Part of the Indonesian region and the west equatorial coast of Africa in JJA and SON and large areas of the Indian Ocean in JJA are also regions with high correlation.

Other methods of model verification are reproducibility (Sperber and Palmer 1996) and analysis of variance (Rowell 1998). In this analysis, we follow Sperber and Palmer (1996), in which reproducibility measures the ratio between the interannual variability extracted from the nine integrations (signal) and the average of the variance estimates from each year based on the nine integrations (noise). Values of reproducibility with $95 \%$ significance are greater than 8 , using the Fisher test. The largest values of reproducibility are found in the eastern Pacific in all seasons (Figs. 14a-d). High reproducibility in this region was also found by Sperber and Palmer (1996) when they analyzed ECMWF model results. Another similar feature to those results occurs in the Indian Ocean, for which the highest reproducibility is found during the northern summer (monsoon season) and in the tropical Atlantic, for which the lowest reproducibility occurs in SON. Northeast Brazil and areas along 

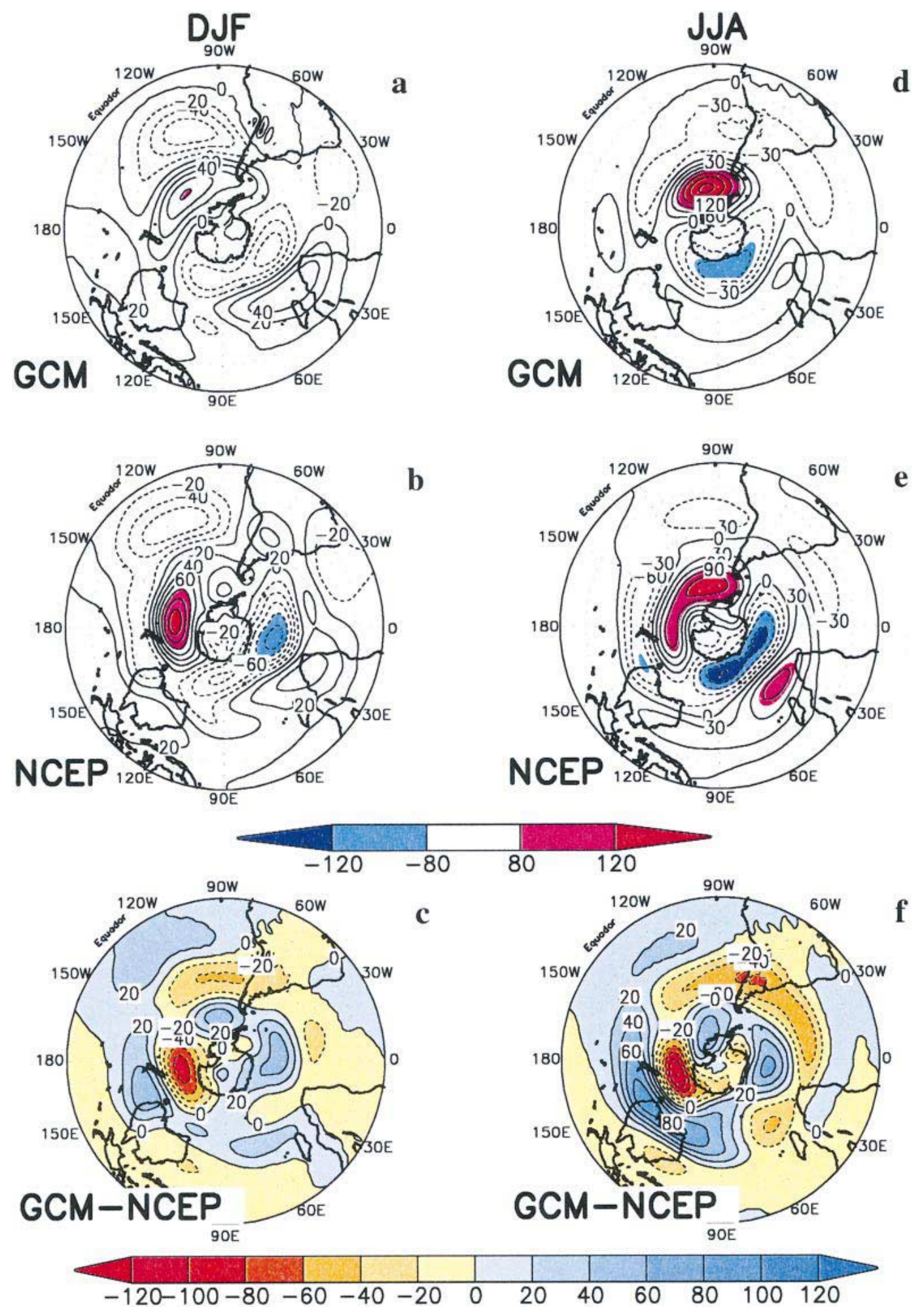

FIG. 9. Same as Fig. 8 but for the Southern Hemisphere. 


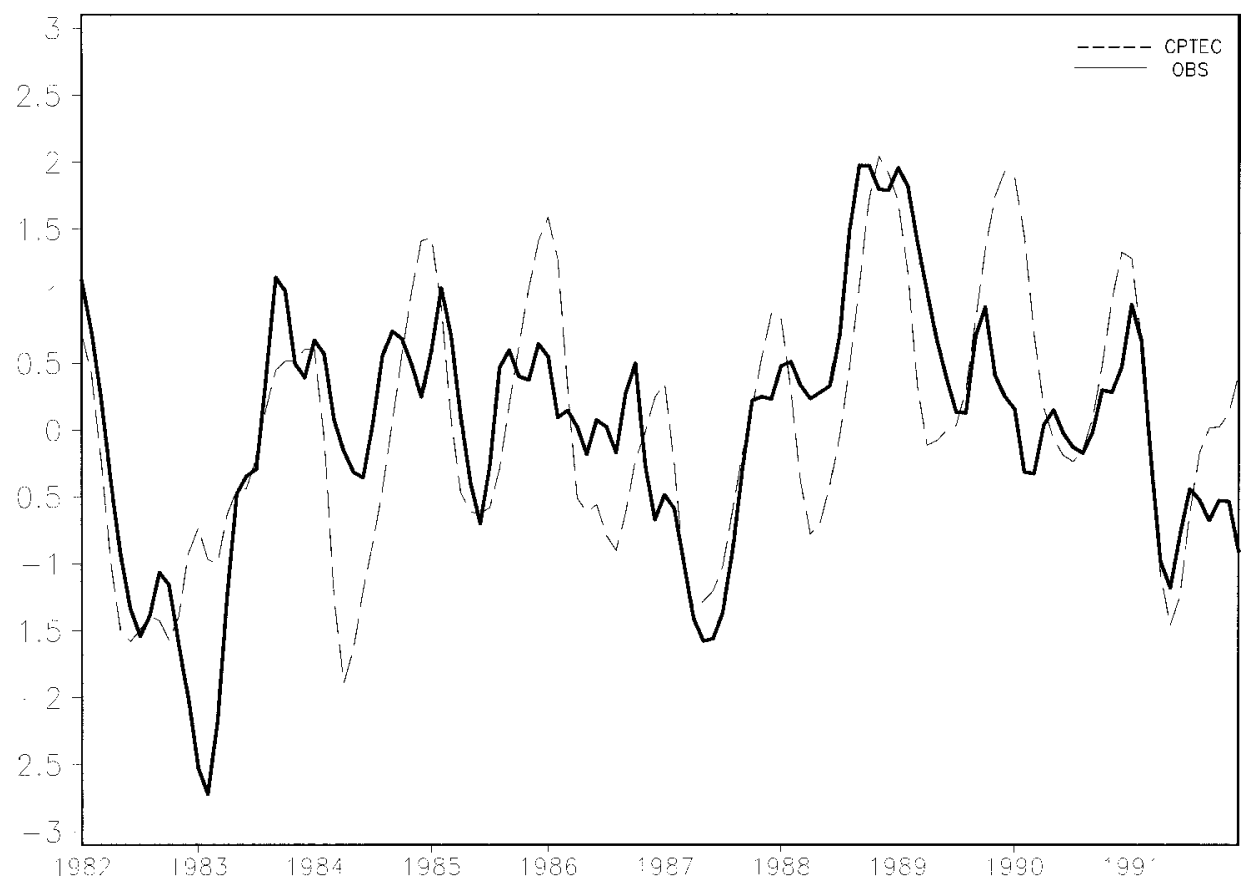

FIG. 10. SOI calculated with observed SLP at Tahiti and Darwin for a 10-yr period (1982-91) (solid line) and calculated from the model results (dashed line).

the north coast of South America also show high values of reproducibility in all seasons.

\section{Summary and conclusions}

The global atmospheric features simulated by the CPTEC-COLA AGCM are shown in this study, with emphasis on the Southern Hemisphere and South America. This model is operationally used for seasonal prediction at CPTEC as one of the tools for the monthly

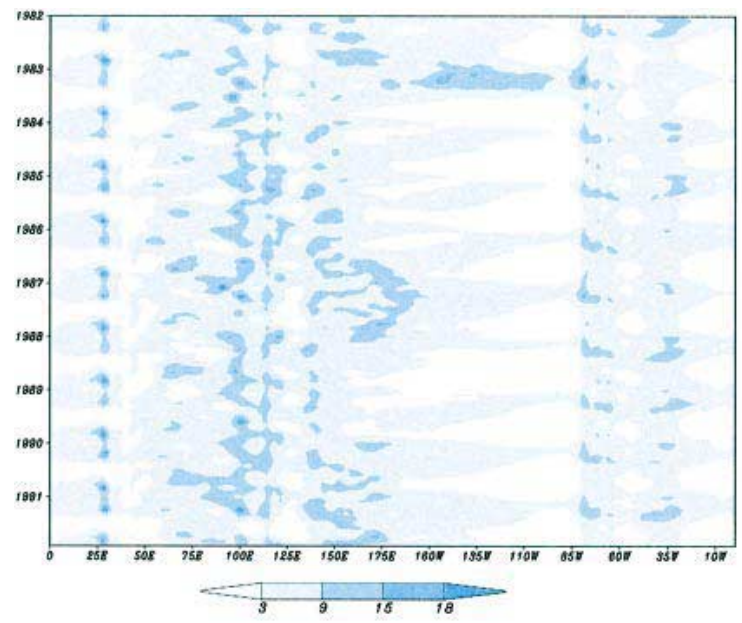

(a) CPTEC/COLA AGCM climate discussions, at which comparison with products available at the International Research Institute is performed.

The model is able to reproduce the precipitation seasonal cycle and the main seasonal global climatological features of the circulation. The gross features of the ITCZ, SPCZ, and SACZ are simulated reasonably well, but precipitation in the tropical (subtropical) sectors of the $\mathrm{SH}$ convergence zones is underestimated (overestimated). There are also large differences over the region

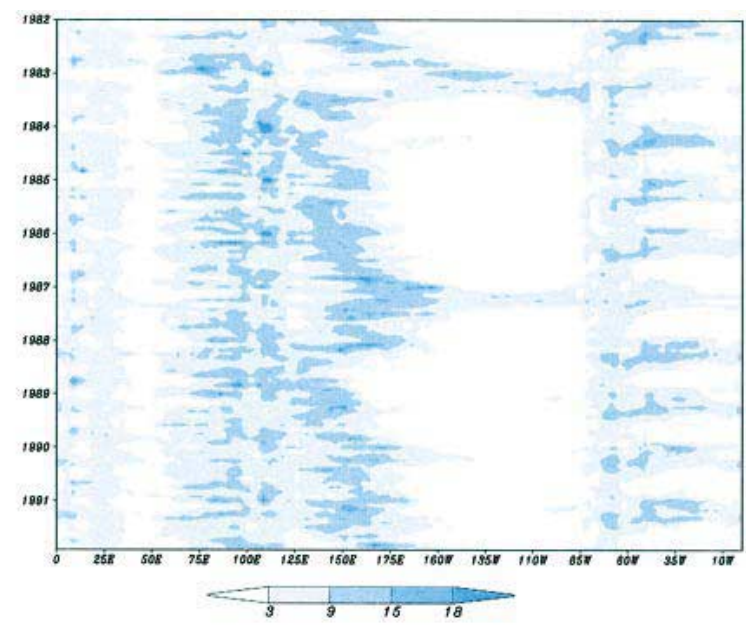

(b) CMAP

FIG. 11. Time-longitude section of precipitation averaged over $5^{\circ} \mathrm{N}-5^{\circ} \mathrm{S}$ for (a) CPTEC-COLA AGCM and (b) CMAP observed data. 

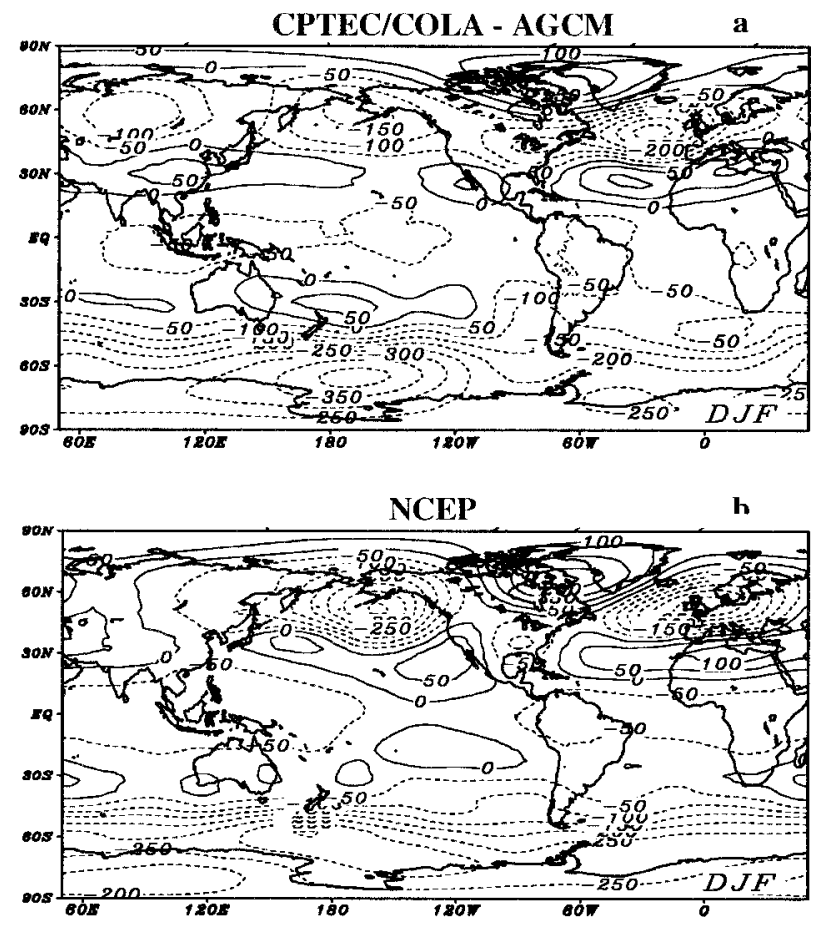

FIG. 12. The 200-hPa geopotential height difference fields for DJF 1982/83 minus DJF 1988/89, (a) as produced by the ensemble mean of the CPTEC-COLA AGCM and (b) from the NCEP-NCAR reanalysis.

of Indonesia where the model underestimates precipitation over the oceanic areas and overestimates precipitation over the land areas. The model exhibits large positive errors in precipitation in the region of Central America during all seasons. The negative precipitation errors over the Indonesian region and the positive precipitation errors over the central and eastern tropical Pacific lead to a northward-displaced ITCZ.

Over South America, the model overestimates precipitation over the Andes and over northeast Brazil and underestimates precipitation over many areas in the interior of the continent, including the Amazon basin. Over Africa, the model generally overestimates precipitation except in the equatorial western region. However, the seasonal variation is simulated very well over these continents.

Although the systematic errors related to precipitation values are larger in the tropical regions, the correlation coefficients are also larger in these regions, showing that the precipitation variability there is better simulated. This happens because of the fact that the source of interannual variability is located in these regions. The reproducibility fields also show that in the tropical regions the signal of seasonal variability is larger than the noise related to the spread among ensemble members.

The deficiency of the model in simulating the amount of precipitation can be partially related to the convection scheme. Differences between CPTEC-COLA and the COLA version (Shukla et al. 2000b) can be related to the use of different convection schemes (Kuo vs RAS), different resolutions (T62 L28 vs R40 L18), and other changes discussed in section 2a. In Shukla et al. (2000b), the analysis was made only for January-FebruaryMarch, whereas here the precipitation results are analyzed in all the four seasons and more emphasis is given to the Southern Hemisphere and South America. A comparison of the CPTEC-COLA results with other model results shows that similar general climatological features are simulated and that part of the precipitation differences can also be related to the convection scheme. The largest errors in the precipitation field occur almost at the same places as the errors observed in the ensemble of models of AMIP (Gates et al. 1999), that is, the Indonesian region, South America, Africa, ITCZ, and SPCZ. However, there are differences in the position and intensity of the Pacific and Atlantic ITCZ. The areas with precipitation of less than $0.1 \mathrm{~mm}$ day $^{-1}$ over tropical Africa and the South Pacific and the Atlantic subtropical highs, which were not simulated well in the AMIP results, are captured very well in the CPTECCOLA AGCM.

The major high- and low-level circulation features such as the subtropical highs and jet streams are captured well by the model although with different intensities when compared with the reanalysis. The Indian monsoon circulation is represented well by the model and shows the association with seasonal precipitation variability over India/southern Asia. The direction of low-level flow over the north coast of South America and the associated seasonal displacement of the Atlantic ITCZ are also simulated well.

The dominance of wavenumber 2 in $\mathrm{NH}$ and wavenumber 1 in the zonal geopotential anomaly in the $\mathrm{SH}$ shows the ability of the model to simulate the main stationary waves of both hemispheres. The vertical structure of zonal wind shows the observed features of jet streams at the subtropical latitudes, including the strengthening of the jets in the winter season of both hemispheres.

The general configuration of the vertical temperature structure is reproduced well, although negative temperature bias is identified in summer and winter at the subtropical and midlatitude regions of the NH troposphere. In the Southern Hemisphere, the vertical structure is simulated very well, and only at high latitudes is a strong negative temperature bias observed in the upper troposphere and stratosphere, a feature that might be related to errors in the reanalysis data.

The ENSO signal is reproduced well by the model in magnitude and variability. Over the Tropics, the model simulates a clear eastward-propagating anomaly in tropical convection and rainfall when anomalously warm tropical Pacific SST associated with El Niño events occur. The ability of the model to simulate ENSO characteristics in the PNA-pattern region is comparable to reanalysis and other GCM simulations.

The energy budget analyses show values of radiative 
ग) D.JF

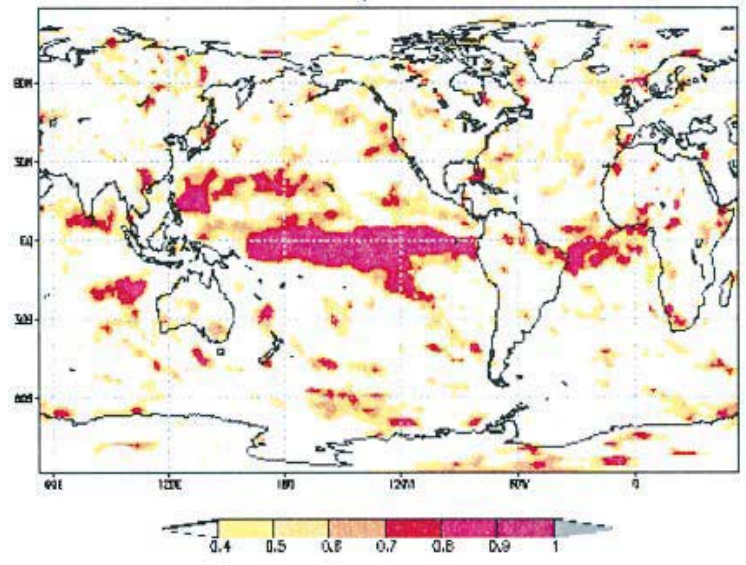

c) JJA

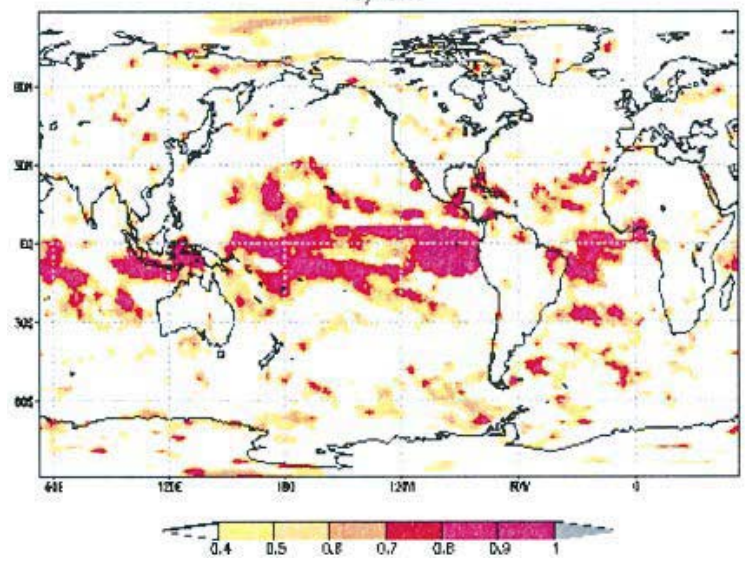

b) MÄM

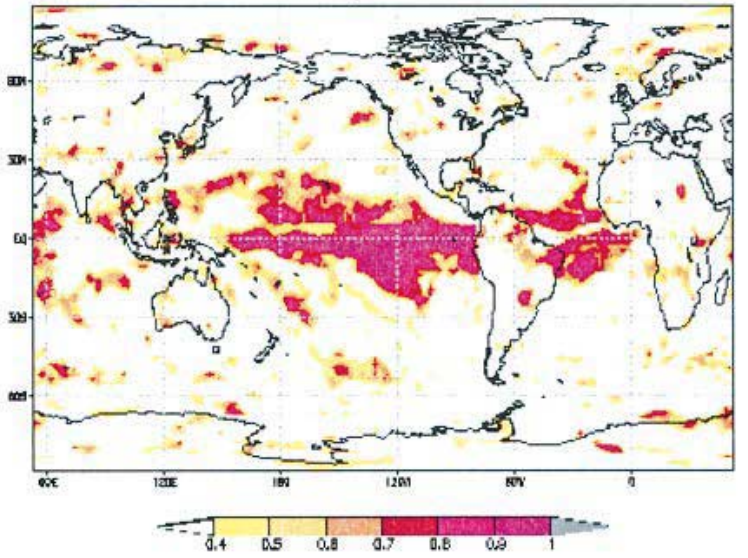

d) $S O N$

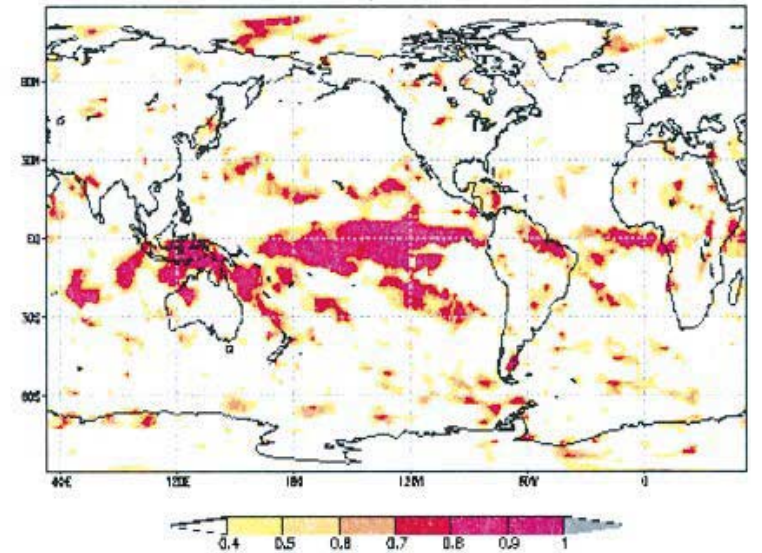

FIG. 13. Correlation coefficient between model anomalies and observed anomalies of precipitation, considering the ensemble mean: (a) DJF, (b) MAM, (c) JJA, and (d) SON.

fluxes that are close to observations, but there are unbalanced fluxes in the atmosphere and at the surface. The net shortwave radiative flux is larger in the model than in the observations, a result that is related to the underestimation of the cloud fraction and to the neglect of the aerosol effect as well as the underestimation of the surface albedo in the model. Larger latent heat fluxes over the oceans in the model results, when compared with the observations, imply more evaporation and a larger precipitation rate. The imposed monthly observed SST prevents the interaction of fluxes between the ocean and the atmosphere, although it occurs between land and atmosphere. The COLA version of a coupled oceanatmosphere GCM, which is being implemented at CPTEC, should overcome this lack of interaction, improving the energy budget. Imbalances in the energy budget were also related to the radiation scheme and cloud-cover calculation, which also calls for improvements in the parameterization schemes. These improvements must occur before the implementation of the CPTEC-COLA coupled model.

Overall assessment of the model climate obtained from the ensemble simulation with nine members for a period of 10 years reveals that the CPTEC-COLA atmospheric GCM T62 L28 version is capable of simulating most of the important features of the atmosphere, thus providing the needed validation of the model for operational weather and seasonal climate forecast guidance.

A step forward of the CPTEC-COLA AGCM as compared with the COLA AGCM is related mainly to the implementations discussed in section 2 , which improved the numerical efficiency of the model and allowed a higher horizontal and vertical resolution, taking into account the changes in the dissipative process. Continuous experiments and simulations are envisaged to improve the model response. This study suggests changes in the convection scheme and improvement of radiation and cloud-cover parameterization. Higher horizontal resolution may also provide more accurate orographic influence on the general atmospheric patterns. The vertical resolution in the atmospheric boundary layer and upper troposphere and lower stratosphere must increase with the increase of the horizontal resolution.

Changes in the algorithms of the CPTEC-COLA 

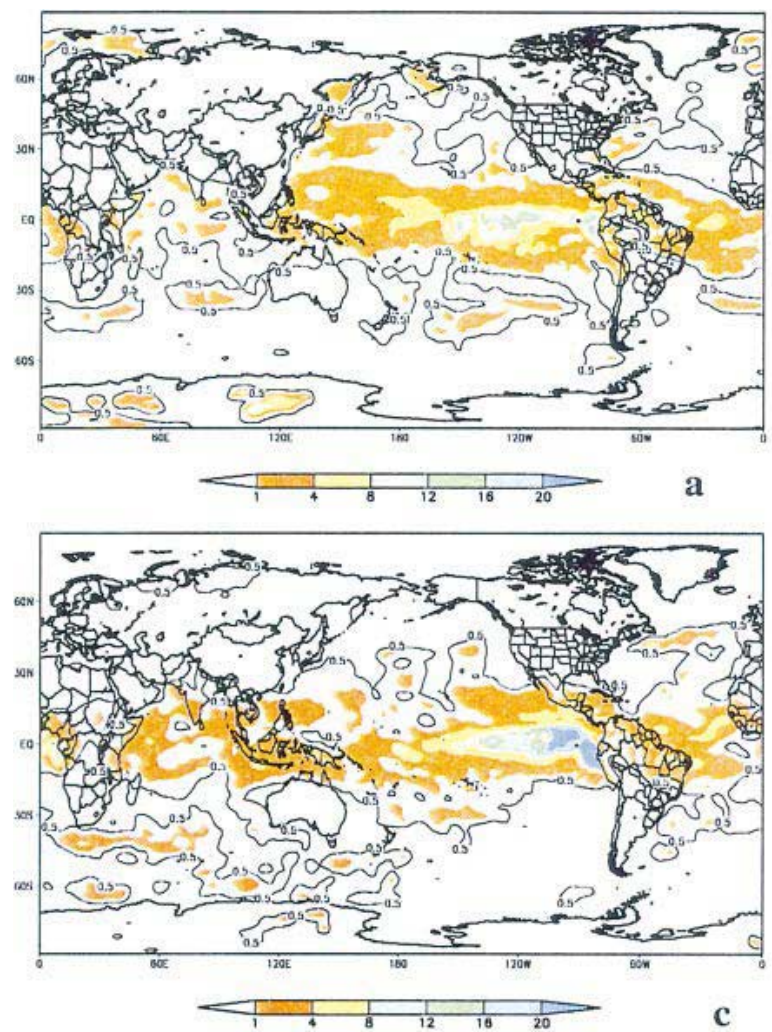
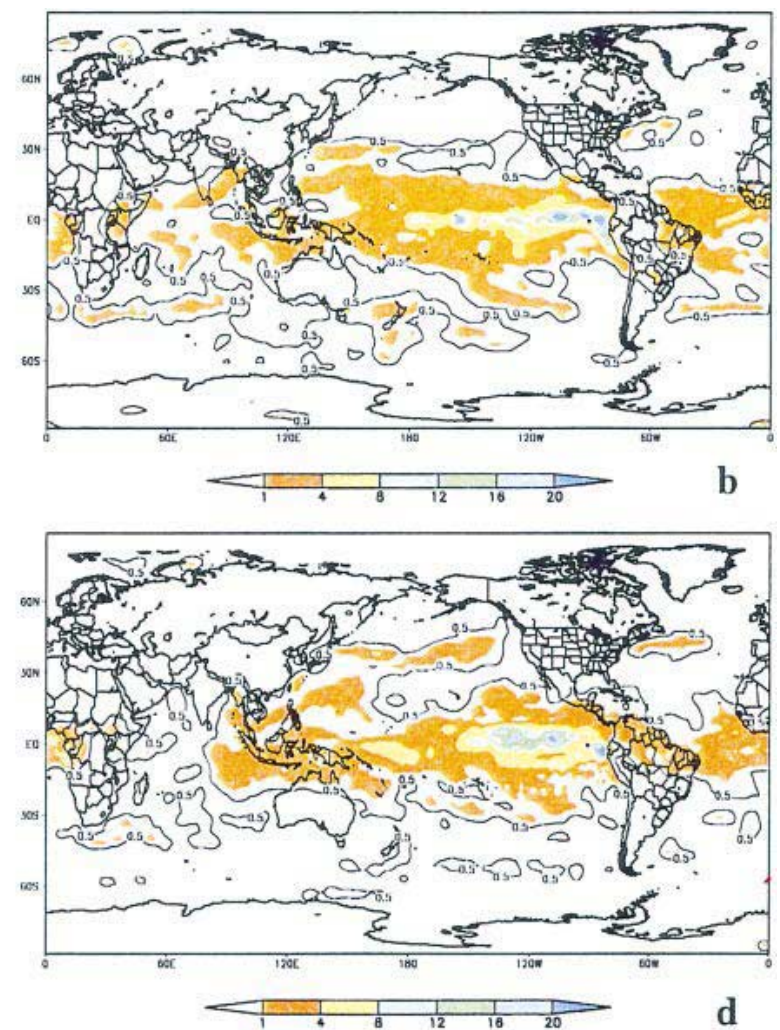

FIG. 14. Reproducibility: (a) DJF, (b) MAM, (c) JJA, and (d) SON.

AGCM and an optimization of the running process are being implemented. They are related to the shortwave dissipative filters to prevent very strong winds, the semiLagrangian scheme to be used in the time integration (Ritchie 1988), reduced and linear grids $\left(\mathrm{T}_{\mathrm{L}}\right)$ (Hortal and Simmons 1991; Courtier and Naughton 1994), and new parameterizations of deep and shallow convection [Albrecht et al. (1986), modified by Souza (1999)]. The computer optimization is related to improvements in the vectorization of the numerical code, introduction of a parallel scheme in the code, change to FORTRAN 90/95 to use facilities of modules, dynamic allocation of memory, object-oriented construction, and application of a matrix product to calculate the Legendre transform. Also, $\mathrm{T}_{\mathrm{L}} 255 \mathrm{~L} 42$ (horizontal spacing of $78 \mathrm{~km}$ and 42 vertical levels) is proposed for use in seasonal climate prediction in an ensemble mode of 51 members.

Acknowledgments. We are very grateful to Drs. V. B. Rao, V. E. Kousky, and P. L. Silva Dias for preliminary review of the manuscript and to the anonymous reviewers for their suggestions.

\section{REFERENCES}

Albrecht, B. A., V. Ramanathan, and B. A. Boville, 1986: The effects of cumulus moisture transports on the simulation of climate with a general circulation model. J. Atmos. Sci., 43, 2443-2462.
Baumgartner, A., and E. Reichel, 1975: The World Water Balance: Mean Annual Global, Continental and Maritime Precipitation and Run-off. Elsevier Scientific, 179 pp.

Brankovic, C., and F. Molteni, 1997: Sensitivity of the ECMWF model northern winter climate to model formulation. Climate Dyn., 13, 75-101.

Cavalcanti, I. F. A., J. A. Marengo, C. C. Castro, G. O. Sampaio, and M. B. Sanches, 1999: Climate prediction of precipitation over South America for DJF 1999/2000 and MAM 2000 using the CPTEC/COLA AGCM. Exp. Long-Lead Forecast Bull., 8, 43-46.

,-- , H. Camargo, C. C. Castro, M. B. Sanches, and G. O. Sampaio, 2000: Climate prediction of precipitation for the Nordeste rainy season of MAM 2000. Exp. Long-Lead Forecast Bull., 9, 49-52.

Courtier, P., and M. Naughton, 1994: A pole problem in the reduced Gaussian grid. Quart. J. Roy. Meteor. Soc., 120, 1389-1407.

Davies, R., 1982: Documentation of the solar radiation parameterizations in the GLAS climate model. NASA Tech. Memo. 83961, $57 \mathrm{pp}$.

Déqué, M., C. Dreveton, A. Braun, and D. Cariolle, 1994: The ARPEGE/IFS atmosphere model: A contribution to the French community climate modelling. Climate Dyn., 10, 249-266.

Gandu, A. D., and P. L. Silva Dias, 1998: Impact of tropical heat sources on the South American tropospheric upper circulation and subsidence. J. Geophys. Res., 103, 6001-6015.

Gates, W. L., 1992: AMIP: The Atmospheric Model Intercomparison Project. Bull. Amer. Meteor. Soc., 73, 1962-1970.

— mospheric Model Intercomparison Project (AMIP). Bull. Amer. Meteor. Soc., 80, 29-55.

Graham, N. E., 1994: Prediction of rainfall in northeast Brazil for MAM 1994 using an atmospheric GCM with persisted SST anomalies. Exp. Long-Lead Forecast Bull., 3, 12-14.

Gregory, D., and P. R. Rowntree, 1990: A mass flux convection 
scheme with representation of ensemble characteristics and stability dependent closure. Mon. Wea. Rev., 118, 1483-1506.

Hack, J. J., J. T. Kiehl, and J. W. Hurrell, 1998: The hydrologic and thermodynamic characteristics of the NCAR CCM3. J. Climate, 11, 1179-1206.

Harshvardhan, D. A. Randall, and T. G. Corsett, 1987: A fast radiation parameterization for general circulation models. J. Geophys. Res., 92, 1009-1016.

Hines, K. M., D. H. Bromwich, and G. J. Marshall, 2002: Artificial surface pressure trends in the NCEP-NCAR reanalysis over the Southern Ocean and Antarctica. J. Climate, 13, 3940-3952.

Holton, J., 1992: An Introduction to Dynamic Meteorology. 3d ed. Academic Press, 511 pp.

Hortal, M., and A. J. Simmons, 1991: Use of reduced Gaussian grids in spectral models. Mon. Wea. Rev., 119, 1057-1074.

Hou, Y. T., 1990: Cloud-radiation dynamics interaction. Ph.D. thesis, University of Maryland, $209 \mathrm{pp}$

Hurrell, J. W., J. J. Hack, B. A. Boville, D. L. Willianson, and J. T. Kiehl, 1998: The dynamical simulation of the NCAR Community Climate Model Version 3 (CCM3). J. Climate, 11, 1207-1236.

Johns, T. C., R. E. Carnell, J. F. Crossley, J. M. Gregory, J. B. Mitchell, C. A. Senior, S. B. Tett, and R. A. Wood, 1997: The Second Hadley Centre Coupled Ocean-Atmosphere GCM: Model description, spinup and validation. Climate Dyn., 13, 103-134.

Kalnay, E., and Coauthors, 1996: The NCEP/NCAR 40-Year Reanalysis Project. Bull. Amer. Meteor. Soc., 77, 437-471.

Kiehl, J. T., and K. E. Trenberth, 1997: Earth's annual global mean energy budget. Bull. Amer. Meteor. Soc., 78, 197-208.

- J. J. Hack, and B. P. Briegleb, 1994: The simulated Earth radiation budget of the National Center for Atmospheric Research Community Climate Model CCM2 and comparisons with the Earth Radiation Budget Experiment (ERBE). J. Geophys. Res., 99, 20 815-20 827.

- — - and J. W. Hurrell, 1998: The energy budget of the NCAR Community Climate Model:CCM3. J. Climate, 11, 1151-1178.

Kinter, J. L., III, and Coauthors, 1997: The COLA atmosphere-biosphere general circulation model. Vol. 1: Formulation. Rep. 51, COLA, Calverton, MD, 46 pp.

Kuo, H. L., 1974: Further studies of the parameterization of the influence of cumulus convection on large-scale flow. J. Atmos. Sci., 31, 1232-1240.

Lacis, A. A., and J. E. Hansen, 1974: A parameterization of the absorption of solar radiation in the earth's atmosphere. J. Atmos. Sci., 31, 118-133.

Lau, K. M., J. H. Kim, and Y. Sud, 1996: Intercomparison of hydrologic processes in AMIP GCMs. Bull. Amer. Meteor. Soc., 77, 2209-2227.

Legates, D. R., and C. J. Willmott, 1990: Mean seasonal and spatial variability in gauge-corrected, global precipitation. Int. J. Climatol., 10, 111-128.

Marengo, J., L. Druyan, and S. Hastenrath, 1993: Observational and modeling studies of Amazonia interannual climate variability. Climatic Change, 23, 267-286.

Marques, R. F. C., and V. B. Rao, 1999: A diagnosis of a long-lasting blocking event over the southeast Pacific Ocean. Mon. Wea. Rev., 127, 1761-1776.

McFarlane, N. A., G. J. Boer, J. P. Blanchet, and M. Laraze, 1992: The Canadian Climate Centre second-generation general circulation model and its equilibrium climate. J. Climate, 5, 1013-1044.

Mellor, G. L., and T. Yamada, 1982: Development of a turbulence closure model for geophysical fluid problems. Rev. Geophys. Space Phys., 20, 851-875.

Moorthi, S., and M. J. Suarez, 1992: Relaxed Arakawa-Schubert: A parameterization of moist convection for general circulation models. Mon. Wea. Rev., 120, 978-1002.

Murphy, J. M., 1988: The impact of ensemble forecasts on predictability. Quart. J. Roy. Meteor. Soc., 114, 463-493.

NMC Development Division Staff, 1988: Research version of the medium range forecast model. NMC Documentation Series 1, 339 pp. [Available from the Development Division, NCEP, Washington, DC 20233.]

Pezzi, L. P., and I. F. A. Cavalcanti, 2000: Testes de sensibilidade usando-se dois esquemas diferentes de convecção, (Sensitivity analysis using two different convection schemes in the CPTEC/ COLA AGCM). Proc. 11th Brazilian Conf. of Meteorology, Rio de Janeiro, Brazil, Meteorological Brazilian Society, 3524-3529.

Pope, V. D., M. L. Gallani, P. R. Rowntree, and R. A. Stratton, 2000: The impact of new physical parameterizations in the Hadley Centre climate model: HadCM3. Climate Dyn., 16, 123-146.

Posey, J. W., and P. F. Clapp, 1954: Global distribution of normal surface albedo. Geofis. Int., 4, 33-48.

Renwick, J. A., 1998: ENSO-related variability in the frequency of South Pacific blocking. Mon. Wea. Rev., 126, 3117-3123.

Reynolds, R. W., and T. M. Smith, 1994: Improved global sea surface temperature analyses using optimum interpolation. J. Climate, 7, 929-948.

Ritchie, H., 1988: Application of the semi-Lagrangian method to a spectral model of the shallow water equations. Mon. Wea. Rev. 116, 1587-1598.

Rowell, D. P., 1998: Assessing potential seasonal predictability with an ensemble of multidecadal GCM simulations. J. Climate, 11, $109-121$.

Sato, N., P. J. Sellers, D. A. Randall, E. K. Schneider, J. Shukla, J. L. Kinter III, Y. T. Hou, and E. Albertazzi, 1989: Effects of implementing the Simple Biosphere Model in a general circulation model. J. Atmos. Sci., 46, 2757-2782.

Shukla, J., and Coauthors, 2000a: Dynamical seasonal prediction. Bull. Amer. Meteor. Soc., 81, 2593-2606.

— D. A. Paolino, D. M. Straus, D. DeWitt, J. L. Fennessy, J. L. Kinter III, L. Marx, and R. Mo, 2000b: Dynamical seasonal predictions with the COLA atmospheric model. Quart. J. Roy. Meteor. Soc., 126, 2265-2291.

Slingo, J. M., 1987: The development of verification of a cloud prediction scheme for the ECMWF model. Quart. J. Roy. Meteor. Soc., 113, 899-927.

Souza, E. P., 1999: Estudo teórico e numérico da relação entre convecção e superfícies heterogêneas na Região Amazônica (Theoretical and numeric study of the relationship between convection and heterogeneous surfaces over Amazon Region). Ph.D. thesis, University of São Paulo, São Paulo, Brazil, 121 pp.

Sperber, K. R., and T. N. Palmer, 1996: Interannual tropical rainfall variability in general circulation model simulations associated with the Atmospheric Model Intercomparison Project. $\mathrm{J}$. Climate, 9, 2727-2750.

Stern, W., and K. Miyakoda, 1995: Feasibility of seasonal forecasts inferred from multiple GCM simulations. J. Climate, 8, 10711085 .

Tiedtke, M., 1983: The sensitivity of the time-mean large-scale flow to cumulus convection in the ECMWF model. Proc. Workshop on Convection in Large-Scale Numerical Models, Reading, United Kingdom, ECMWF, 297-316

Wallace, J. M., 1983: The climatological mean stationary waves: Observational evidence. Large-Scale Dynamical Processes in the Atmosphere, B. Hoskins and R. Pearce, Eds., Academic Press, 27-53.

Ward, N., and C. K. Folland, 1991: Prediction of seasonal rainfall in the north Nordeste of Brazil using eigenvectors of sea-surface temperature. Int. J. Climatol., 11, 711-743.

Willmott, C. J., C. M. Rowe, and Y. Mintz, 1985: Climatology of the terrestrial seasonal water cycle. J. Climatol., 5, 589-606.

Xie, P., and P. A. Arkin, 1997: Global precipitation: A 17-year monthly analysis based on gauge observations, satellite estimates, and numerical model outputs. Bull. Amer. Meteor. Soc., 78, 2539-2558.

Xue, Y., P. J. Sellers, J. L. Kinter III, and J. Shukla, 1991: A simplified biosphere model for global climate studies. J. Climate, 4, 345364. 